\title{
Hydrographic structure of overflow water passing through the Denmark Strait
}

\author{
by \\ Dana M. Mastropole \\ B.S., Physics \\ Georgetown University (2012)
}

Submitted to the Joint Program in Physical Oceanography

in partial fulfillment of the requirements for the degree of

Master of Science

at the

MASSACHUSETTS INSTITUTE OF TECHNOLOGY

and the

WOODS HOLE OCEANOGRAPHIC INSTITUTION

September 2015

(C)2015 Dana M. Mastropole

All rights reserved.

The author hereby grants to MIT and WHOI permission to reproduce and to distribute publicly paper and electronic copies of this thesis document in whole or in part in any medium now known or hereafter created.

Author

Joint Program in Physical Oceanography Massachusetts Institute of Technology \& Woods Hole Oceanographic Institution

August 7th, 2015

Certified by

Robert S. Pickart

Senior Scientist

Woods Hole Oceanographic Institution

Thesis Supervisor

Accepted by

Glenn R. Flierl

Chairman, Joint Committee for Physical Oceanography Massachusetts Institute of Technology Woods Hole Oceanographic Institution 


\title{
Hydrographic structure of overflow water passing through the Denmark Strait
}

\author{
by \\ Dana M. Mastropole \\ Submitted to the Joint Program in Physical Oceanography \\ Massachusetts Institute of Technology \\ \& Woods Hole Oceanographic Institution \\ on August 7th, 2015, in partial fulfillment of the \\ requirements for the degree of \\ Master of Science
}

\begin{abstract}
Denmark Strait Overflow Water (DSOW) constitutes the densest portion of North Atlantic Deep Water, which feeds the lower limb of the Atlantic Meridional Overturning Circulation (AMOC). As such, it is critical to understand how DSOW is transferred from the upstream basins in the Nordic Seas, across the Greenland-Scotland Ridge, and to the North Atlantic Ocean. The goal of this study is to characterize the hydrographic structure of the different DSOW constituents at the sill before the water descends into the Irminger Sea using temperature and salinity (T/S) data from 111 shipboard crossings in the vicinity of the sill, collected between 1990 and 2012. The individual realizations indicate that weakly stratified "boluses" of DSOW frequent the sill and contribute the densest water to the overflow. This study also characterizes the structure, size, and location of the boluses and relates them to the $\mathrm{T} / \mathrm{S}$ modes found at the sill. Lastly, historical hydrographic data from the Nordic Seas are used to make inferences regarding the origin of the boluses.
\end{abstract}

Thesis Supervisor: Robert S. Pickart

Title: Senior Scientist

Woods Hole Oceanographic Institution 


\section{Acknowledgments}

I would first like to thank my advisor, Dr. Robert Pickart, for all of his help and guidance throughout my time in graduate school and in writing this thesis.

I would like to thank Carolina Nobre for all of her help as well. Carolina has been a great teacher and friend, and I attribute much of my knowledge of MATLAB and Illustrator to her. She was also the mastermind behind the code I used to eliminate density inversions from the data presented in this thesis.

I would also like to thank Héðinn Valdimarsson, Kjetil Våge, Kerstin Jochumsen, Detlef Quadfasel, Gerd Krahmann, Bert Rudels, and James Girton for providing data.

Finally, I would like to say a big thank you to Sarvesh Garimella who has been working hard to help me format this thesis and submit it on time. I also want to thank him for the emotional support he has given me over the past three years and for letting me bounce ideas about my research off of him.

Financial support for this work was provided by the National Science Foundation grant OCE-0959381. 


\section{Contents}

1 Introduction $\quad 15$

2 Data and Methods $\quad 19$

2.1 The Látrabjarg Line . . . . . . . . . . . . . . . . . . . . . . . . . . . . . . . 19

2.2 Hydrographic Data . . . . . . . . . . . . . . . . . . . . . 20

2.2.1 Occupations of Látrabjarg Line . . . . . . . . . . . . . . . . . . . . 20

2.2.2 Historical Hydrographic Dataset of the Nordic Seas . . . . . . . . . . . 21

2.3 Gridding the Data . . . . . . . . . . . . . . . . . 21

2.3 .1 The Interpolator $\ldots \ldots \ldots \ldots$. . . . . . . . . . . . . . 21

2.3.2 Extrapolation . . . . . . . . . . . . . . . . . . . . . 22

2.3.3 Station Spacing and Grid Resolution . . . . . . . . . . . . . 22

2.3.4 Interpolating in Density . . . . . . . . . . . . . . . . . . . 23

2.3.5 Re-gridding and Smoothing . . . . . . . . . . . . . . . 24

2.3.6 Hybrid Gridding Scheme . . . . . . . . . . . . . . . . 24

2.4 Defining Boluses of Overflow Water in Synoptic Sections . . . . . . . . . 25

$\begin{array}{llr}3 & \text { Results } & 27\end{array}$

3.1 Mean State of Denmark Strait . . . . . . . . . . . . . . . . . . . 27

3.2 Synoptic Variability of Denmark Strait . . . . . . . . . . . . . . . 28

3.2.1 Characterizing Denmark Strait Boluses . . . . . . . . . . . . . . . . . . 29

3.2.2 Boluses and the Hydrographic Structure of Denmark Strait . . . . . . 30

3.2 .3 Isopycnal Heaving and Transport . . . . . . . . . . . . . . . . . . 31

3.3 Volumetric T/S Modes and the Origin of Bolus Water . . . . . . . . . . . 32

3.3.1 Features Seen in Volumetric T/S Plots . . . . . . . . . . . . . . . 32

3.3.2 Comparison of Mode and Bolus Water in Denmark Strait . . . . . . . 32 
3.3.3 Origin of the Mode Water Upstream of Denmark Strait . . . . . . . 33

4 Conclusion $\quad 35$

4.1 Summary . . . . . . . . . . . . . . . . . . . 35

4.2 Discussion . . . . . . . . . . . . . . . . . . 36

$\begin{array}{lr}\text { A Tables } & 39\end{array}$

$\begin{array}{ll}\text { B Figures } & 43\end{array}$ 


\section{List of Tables}

A.1 List of the 111 hydrographic occupations of Denmark Strait across the Látrabjarg Line. Part (a) contains identification information for the cruises listed in the "cruise" column of part (b) . . . . . . . . . . . . . . . . . . 40

A.2 Mean and standard errors of the potential temperature, salinity, and potential density of boluses and non-bolus overflow. The last column contains transport estimates of the total overflow water (east of the Greenland shelf) in the presence and absence of boluses. Transports were estimated using a constant velocity of $0.2 \mathrm{~m} / \mathrm{s}$, a value characteristic of the overflow (Våge et al., 2011). . 41 


\section{List of Figures}

B-1 Schematic of the currents flowing through Denmark Strait. The sill is located at the Látrabjarg line (drawn in black). The $500 \mathrm{~m}$ and $1000 \mathrm{~m}$ isobaths are contoured in grey. . . . . . . . . . . . . . . . . . . . . . 44

B-2 The months and years of all the occupations (a) and the occupations with boluses (b). The marker's opacity indicates the number of occupations conducted in a given month and year. . . . . . . . . . . . . . . . 45

B-3 The Látrabjarg line (draw in black) and CTD stations in green. The CTD stations are from 111 shipboard crossings of Denmark Strait. The $500 \mathrm{~m}$ and $1000 \mathrm{~m}$ isobaths are contoured in grey. . . . . . . . . . . . . . . . . . 46

B-4 The cruise tracks (a) and corresponding echo-sounder measurements (b) from 5 cruises that occupied Denmark Strait. The Látrabjarg line (black) is created from the best-fit line of the cruise tracks. The bend in KN-194 is removed from this calculation. The echo-sounder data are filtered to create the corresponding bathymetric contour in (b). The $500 \mathrm{~m}$ and $1000 \mathrm{~m}$ isobaths are contoured in grey in $(\mathrm{a}) \ldots \ldots \ldots$. . . . . . . . . . . . . . . . 47

B-5 Locations of bathymetric features in Denmark Strait across the Látrabjarg line. The approximate locations of the currents are labeled in color. The acronyms are EGC $=$ East Greenland Current; NIJ = North Icelandic Jet;

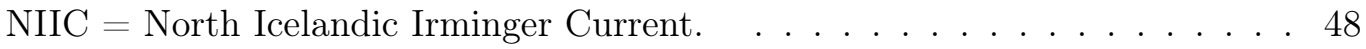

B-6 Station locations (a) and depths (b) taken on cruise P-294 in the vicinity of the Látrabjarg line. Stations were first projected onto the Látrabjarg line (b, red) and then shifted (b, blue). The bathymetry is contoured in grey. . . . . . 49

B-7 The number and location (in vertical sections along the Látrabjarg line) of data that are modified to eliminate density inversions. . . . . . . . . . . 50 
B-8 The mean potential temperature (a), salinity (b), and $N^{2}(\mathrm{c})$ of the Látrabjarg line. Potential density is contoured in black and the 27.8 isopycnal, which indicates the top of the overflow, is highlighted in pink. The lines above each subplot indicate the number of independent samples across the section. . . . . 51

B-9 Realizations of (a) boluses, (b) lower mode water, and (c) upper mode water identified in synoptic sections across Denmark Strait. . . . . . . . . . . . 52

B-10 The composite bolus (a), background (b), and anomaly (c) sections of potential temperature. Potential density is contoured in black and the 27.8 isopycnal, which indicates the top of the overflow, is highlighted in pink. The lines above each subplot indicate the number of independent samples across the section. In the anomaly subplots, the dashed line represents the number of bolus samples and the solid line represents the number of background samples. The grey crosses indicate regions of the plot where the spread in bolus and background values do not overlap. . . . . . . . . . . . . . . . 53

B-11 The composite bolus (a), background (b), and anomaly (c) sections of salinity. Potential density is contoured in black and the 27.8 isopycnal, which indicates the top of the overflow, is highlighted in pink. The lines above each subplot indicate the number of independent samples across the section. In the anomaly subplots, the dashed line represents the number of bolus samples and the solid line represents the number of background samples. The grey crosses indicate regions of the plot where the spread in bolus and background values do not overlap. . . . . . . . . . . . . . . . . . . . . . 54

B-12 The composite bolus (a), background (b), and anomaly (c) sections of potential density. The 27.8 isopycnal, which indicates the top of the overflow, is highlighted in pink. The lines above each subplot indicate the number of independent samples across the section. In the anomaly subplots, the dashed line represents the number of bolus samples and the solid line represents the number of background samples. The grey crosses indicate regions of the plot where the spread in bolus and background values do not overlap. . . . . . . . 55 
B-13 The composite bolus (a), background (b), and anomaly (c) sections of $N^{2}$. Potential density is contoured in black and the 27.8 isopycnal, which indicates the top of the overflow, is highlighted in pink. The lines above each subplot indicate the number of independent samples across the section. In the anomaly subplots, the dashed line represents the number of bolus samples and the solid line represents the number of background samples. The grey crosses indicate regions of the plot where the spread in bolus and background values do not overlap. . . . . . . . . . . . . . . . 56

B-14 Mean vertical displacement of the isopycnals in Denmark Strait due to the passage of boluses (color). Overlaid on this is the potential density (contours) of the background state (in the absence of boluses). The grey crosses indicate regions of the plot where the spread in bolus and background values do not overlap. . . . . . . . . . . . . . . . . . . . 57

B-15 The volumetric $\mathrm{T} / \mathrm{S}$ plot of all the measurements from all the occupations of the Látrabjarg line. The pink density contour represents the upper, density bound of the overflow. The thermohaline indices of Irminger water, polar surface water, return Atlantic water, and Arctic origin water are indicated by black dots. . . . . . . . . . . . . . . . . . . . . 57

B-16 The volumetric $\mathrm{T} / \mathrm{S}$ plot of the densest measurements from the Látrabjarg line. In (a) The upper (warmer) and lower (colder) T/S modes are outlined in pink. In (b) the mean temperature and salinity of each bolus is indicated by a green star. . . . . . . . . . . . . . . . . . . . . 5 58

B-17 The number of grid points representing lower mode water (upper subplot) and upper mode water (lower subplot) and whether they are contained in boluses. . . . . . . . . . . . . . . . . . . . . . 59

B-18 The percent composition of lower and upper mode water for each of the 46 boluses. . . . . . . . . . . . . . . . . . . . . 6 60

B-19 The vertical extent (i) and proximity to the surface (ii) of lower mode (a) and upper mode (b) water in the Nordic Seas. Only water above sill depth $(650 \mathrm{~m})$ is considered. The black contours denote the dynamic height of the Iceland Sea gyre, and the bathymetry is contoured in grey. . . . . . . . . . . 61 


\section{Chapter 1}

\section{Introduction}

The Atlantic Meridional Overturning Circulation (AMOC) has been the focus of scientific study for many years, because of its important role in regulating Earth's climate. Investigations of the circulation system of the Nordic Seas seek to understand the complex physical processes that feed the lower limb of the AMOC. Denmark Strait Overflow Water (DSOW) is the largest and densest contributor of the lower limb, supplying approximately half of the dense water in the Deep Western Boundary Current (Dickson et al., 2008). Dickson et al. (2008) defined DSOW as water with potential density values greater than $27.8 \mathrm{~kg} / \mathrm{m}^{3}$, and for the reasons outlined in that paper, DSOW will be defined as such in this thesis. While the hydrographic structure and variability of DSOW have been investigated by a robust collection of field observations and modeling studies, there remain gaps in our understanding of this part of the AMOC. Many of these observational studies consist of mooring data and a few synoptic shipboard sections. This study presents over two decades of synoptic sections across the Denmark Strait sill and characterizes the hydrography of the waters flowing through it.

In light of the past two decades of research on the Nordic Seas circulation system, it is thought that DSOW approaches the sill via three pathways - the East Greenland Current (EGC), the North Icelandic Jet (NIJ), and the Separated East Greenland Current (Separated EGC) (Figure B-1). Maruitzen (1996) proposed the first pathway, explaining that warm Atlantic Water in the Norwegian Atlantic Current cools and densifies within the boundary current around the Greenland and Iceland seas and demonstrated that this cooled Atlantic Water comprises DSOW. Specifically, the Atlantic water enters the Nordic Seas east 
of Iceland, and returns southward in the shelfbreak EGC as cooler return Atlantic water. Additionally, the shelfbreak EGC carries fresh, cool surface water called polar surface water (Rudels et al., 2002). This water is formed by the melting of sea ice from the Arctic Ocean.

Jónsson and Valdimarsson (2004) subsequently discovered the NIJ - a deep, southward flowing jet on the Iceland shelf. Later field studies on the transport and hydrographic properties of the jet have revealed that it contributes the densest third of the overflow water at the sill (Våge et al., 2011b, 2013). The overflow water in the NIJ is referred to as Arctic origin water, since it is believed to be formed in the Iceland Sea due to wintertime convection. Våge et al. (2011) hypothesize that the NIJ is the lower limb of a local overturning loop, whose upper limb is the warm and salty North Icelandic Irminger Current (NIIC) (Figure B-1).

More recently, Våge (2013) identified a third pathway of overflow water called the Separated EGC, which is a bifurcation of the EGC. It is formed by anti-cyclones that coalesce into a persistent, surface-intensified jet. A combination of the wind stress and the bathymetry near the Greenland coast spins up these anti-cyclones.

The overflow water at the sill exhibits large fluctuations in its properties. Previous observational studies have demonstrated that the structure of the overflow changes on periods of 1 to 5 days (Ross 1982; Bruce 1995; Käse et al., 2003). Using hydrographic sections south of Denmark Strait, Cooper (1955) attributed this variability to the transit of large, cold, intermittent masses of Norwegian Sea water called boluses. The existence of boluses was later supported by work conducted by Worthington (1969), who observed periods of cold, fast currents interspersed with warm, slow currents in mooring data close to the sill. Since then, boluses have been identified in observational datasets and numerical models (Agaard and Malmberg 1978; Bruce 1995; Krauss 1996; Spall and Price 1998; Rudels 1999; Girton and Stanford 2003; Käse et al., 2003; Macrander et al., 2007; Koszalka and Haine 2013), but the nature of these features remains poorly understood.

Several theories postulate bolus formation and their frequency of passage. Smith (1976) hypothesized that boluses form from baroclinic instability of the overflow and found that the period of the most unstable wave in an idealized flow through Denmark Strait matched the period of variability in current meter and hydrographic records of the overflow. However, nonlinear processes are observed south of Denmark Strait, such as the rapid descent of DSOW over the sill and the subsequent production of surface eddies, which indicates a 
breakdown in Smith's linear model. An alternate theory was subsequently proposed after the discovery of an unstable, southward flowing, barotropic surface jet in Denmark Strait (Fristedt et al., 1999). The jet has unstable growth rates comparable to the baroclinic wave proposed by Smith (1976) and is an alternate mechanism responsible for fluctuations in the overflow. Other numerical modeling studies have proposed different mechanisms investigating the influence of topography and stratification on bolus formation (Jungclaus and Backhaus, 1994; Jiang and Garwood 1996; Krauss and Käse, 1998; Spall and Price 1998; Käse and Oschlies 2000; Shi et al., 2001).

The presence of boluses in the overflow has several implications for regional and global circulation. First, their low temperatures and salinities influence the properties of NADW (Rudels 1999; Tanhua et al., 2005). Second, the presence of a bolus increases the thickness and thus transport of the overflow at the sill (Ross 1982). When averaging the transport of DSOW over times scales longer than the bolus period, however, the transport is steady (Dickson and Brown 1994). Additionally, there does not appear to be any seasonal variability in the overflow (Jonsson, 1999; Jochumsen et al., 2012). Finally, there is evidence in the form of laboratory experiments, mooring and satellite observations, and modeling studies that boluses spin up cyclones south of the sill (Smith 1975; Bruce 1995; Spall and Price 1998; von Appen, 2013). In turn, these cyclones entrain water downstream of the sill and contribute to the mixing, and subsequent modification, of DSOW.

This study seeks to characterize the hydrographic structure of the different DSOW constituents at the sill, before the water descends into the Irminger Basin. It presents temperature and salinity data from 111 shipboard crossings in the vicinity of the sill, collected between 1990 and 2012. This thesis will discuss features seen in the mean section and connect them to the water masses and currents upstream of Denmark Strait. This work also presents an objective definition to identify boluses in individual sections, characterizes their structure, size, and location, and relates them to the volumetric T-S modes found at the sill. Lastly, an historical dataset from the Nordic Seas is used to make inferences regarding the origin of the boluses. 


\section{Chapter 2}

\section{Data and Methods}

\subsection{The Látrabjarg Line}

The data discussed in this study consist of 111 hydrographic sections taken across Denmark Strait between 1990 and 2012 (Table A.1, Figure B-2, Figure B-3) The data are from conductivity-temperature-depth (CTD) stations along a section called the Látrabjarg line. The Marine Research Institute of Reykjavik (MRI) occupied this line between 1993 and 1997 as a part of the Nordic contribution to the World Ocean Circulation Experiment (NordicWOCE), whose aim was to collect data on ocean currents, hydrography, and chemistry to inform numerical models (Nordic-World, 2009). These occupations were included in this study. Between 1997 and 1999, MRI also participated in the Variability of Exchanges in the Northern Seas (VEINS) program, which investigated changes in fluxes between the Arctic and Atlantic Oceans (Variability, 2000). Additional occupations come from this program. A total of 88 synoptic sections along the standard, MRI Látrabjarg line, and 23 synoptic sections in the vicinity of the Látrabjarg line, comprise the data presented in this study. The dates and cruise information are summarized in Table A.1.

For the purposes of this study, the Látrabjarg line is redefined: the line is constructed from 5 cruise tracks rather than the traditional MRI station locations because these cruises obtained high-resolution echo-sounder measurements to map the sea floor. The new line is constructed using linear, least-squares regression. However, since cruise KN-194 measured the bathymetry in two segments, the second segment is ignored while creating the regression line (Figure B-4). The start and end points of the new line have geographic coordinates $\left(66^{\circ} 46.0^{\prime} \mathrm{N} 29^{\circ} 45.8^{\prime} \mathrm{W}, 65^{\circ} 29.1^{\prime} \mathrm{N} 25^{\circ} 35.9^{\prime} \mathrm{W}\right)$. The depth of the sea floor along the new 
Látrabjarg line is estimated from the echo-sounder data. All the depth measurements were projected onto the regression line, and fluctuations in the bathymetry with wavelengths shorter than $3.5 \mathrm{~km}$ were filtered out using a first order, low-pass Butterworth filter (Figure B-4).

The bathymetry of Denmark Strait along the Látrabjarg line has some notable features - the Greenland and Iceland shelves and their associated shelf breaks, the trough, and the ledge (Figure B-5). In this thesis, the trough refers to the region between the Greenland and Iceland shelf breaks that is below $250 \mathrm{~m}$. Furthermore, the lower trough refers to the region below $500 \mathrm{~m}$, or the ledge immediately offshore of the Greenland shelf.

A total of 1136 CTD stations were projected onto the Látrabjarg line. Only CTD stations within $75 \mathrm{~km}$ of the line are considered in this study, $90 \%$ of which fall within 5 $\mathrm{km}$ of the line (Figure B-3). Four cruises took CTD stations more than $20 \mathrm{~km}$ from the Látrabjarg line. Of these cruises, three are shifted laterally so cast depths line up with the bathymetry. The tendency for water to follow bathymetric contours justifies shifting CTD stations in such a way. An example of this adjustment is shown in (Figure B-6). For the same reason, individual station locations along the new Látrabjarg line were also adjusted. Because of steep gradients in Denmark Strait's bathymetry, the projected station data sometimes extend beyond the sea floor or fall short of it. To correct this issue, each station was shifted horizontally no more than $2 \mathrm{~km}$ (a distance smaller than the standard horizontal grid spacing, which is discussed below) to minimize the distance between the bottom of the cast and the ocean floor.

From hereon the new Látrabjarg line will be referred to as simply the Látrabjarg line.

\subsection{Hydrographic Data}

\subsubsection{Occupations of Látrabjarg Line}

The hydrographic data used in this study were collected with Sea-Bird CTDs and the data were processed using SPE data routines (SBE, 2014). Additionally in September 1998, three hydrographic sections were taken aboard the F/S Poseidon using expendable profilers (XCP/XCTD). Girton and Sanford (2001) discuss the calibration of these profilers. Potential temperature and potential density, hereafter referred to as "temperature" and "density," are calculated in this study from processed CTD temperature, salinity, and pressure data using 
algorithms in version 3.3 of the CSIRO Seawater Library (CSIRO, 2010).

Fluctuations in temperature, salinity, and density with wavelengths shorter than $7 \mathrm{~m}$ are filtered out using a fifth order, low-pass Butterworth filter. Density inversions with magnitudes greater than $0.02 \mathrm{~kg} / \mathrm{m}^{3}$ are also removed by manually adjusting corresponding values of temperature and salinity. Adjustments were made to 693 data points, which is roughly $0.2 \%$ percent of the data. (Figure B- 7 ).

\subsubsection{Historical Hydrographic Dataset of the Nordic Seas}

The historical hydrographic dataset used in this study consists of shipboard CTD measurements and Argo profiles, and it covers the region between $65-71^{\circ} \mathrm{N}$ and $8-28^{\circ} \mathrm{W}$ from 1980 to 2015. The initial version of the database is described in detail in Våge et al. (2013), and the updated version is described in Våge et al. (2015).

\subsection{Gridding the Data}

This section first presents an overall description of the interpolator used to grid the vertical sections. Then, each step of the gridding process is discussed in detail. The process is summarized as follows: 1) Data are extrapolated past the sea floor. 2) Data for each occupation are interpolated onto a low, medium, or high-resolution grid according to the station spacing, where the upper portion of the water column is gridded depth space and the lower portion is gridded in density space. 3) After smoothing, the data are re-interpolated onto the highest resolution grid.

\subsubsection{The Interpolator}

The CTD data are interpolated onto a standard grid in order to create vertical sections of temperature, salinity, and density. These gridded sections are created using a Laplacian spline interpolator with tension (Smith and Wessel, 1990). This interpolator grids data onto surfaces whose curvature can be adjusted by changing a parameter called tension - the higher the tension, the lower the curvature. Tensions ranged from 0 to 2 for temperature and salinity and 0 to 5 for density. The same tension is assigned to temperature and salinity for a given section, since both properties reflect the same distribution of water masses. Density is typically assigned larger values for tension in order to create smooth density fields. Due 
to temporal variability in the hydrographic structure of Denmark Strait, tensions are set at different values for each occupation. The interpolator also includes a parameter called the search radius, which limits the distance (in number of grid points) within which the interpolator searches for data around an empty grid point. This parameter is chosen to be 20 for all occupations, ensuring every grid point is assigned a value.

\subsubsection{Extrapolation}

Due to Denmark Strait's steeply sloping bathymetry, the interpolator fails to assign values to grid-points close to the sea floor where only data downslope of these grid-points are detected. Consequently, CTD cast data are extrapolated past the sea floor before interpolation. Temperature, salinity, and density gradients in the trough, however, change according to the magnitude of extrapolation. Extrapolating station data to greater depths results in

sharper and steeper gradients in water properties, while minimal extrapolation allows these properties mix through the bottom of the ocean floor. To balance these effects, the extent of extrapolation varied on a per cast basis and depended on the hydrography of the section. Most cast data are extrapolated $50 \mathrm{~m}$, however, 34 casts are extrapolated $100 \mathrm{~m}$ and 5 are not modified.

Data are extrapolated at $1 \mathrm{~m}$ increments and are assigned temperature and salinity values identical to those of the deepest measurement in the cast. This method is chosen instead of using vertical trends to prevent the fabrication of water masses in gridded sections. Since the data are interpolated in depth and density space (explained below), density is also extrapolated beyond the value of the deepest cast measurement. Extrapolating density also corrected issues associated with interpolation near Denmark Strait's steeply sloping bottom. Extrapolated data are assigned density values that increased by $0.0005 \mathrm{~kg} / \mathrm{m}^{3}$ for every 1 $m$ increase in depth. Water in the trough of Denmark Strait is typically homogeneous in density, so a small density increment is chosen to prevent falsely creating dense, stratified features in the synoptic sections.

\subsubsection{Station Spacing and Grid Resolution}

The horizontal spacing between CTD stations along the Látrabjarg Line line varies considerably among occupations, ranging from approximately $6 \mathrm{~km}$ to $25 \mathrm{~km}$. If the grid spacing is much larger than the average station spacing, many details in the hydrographic struc- 
ture are smoothed out. On the other hand, if the grid spacing is much smaller than the average station spacing, large-scale features tend to fragment. For these reasons, each occupation is initially interpolated onto one of three grids with different horizontal, spatial resolutions according to its station spacing. Most of the occupations are interpolated onto a low-resolution $(10 \mathrm{~m} \times 10 \mathrm{~km})$ grid. The remaining occupations are interpolated onto either a medium-resolution $(10 \mathrm{~m} \times 5 \mathrm{~km})$ or high-resolution $(10 \mathrm{~m} \times 2.5 \mathrm{~km})$ grid.

All grids have the same vertical resolution, since all measurements are taken at the same depth interval of $1 \mathrm{~m}-2 \mathrm{~m}$. Although the profiles are highly resolved, grid spacing is $10 \mathrm{~m}$ in the vertical due to the nature of the interpolator's search radius. Since the interpolator weights adjacent grid points equally when assigning values to empty grid points, these values are chosen to be weighted equally by water $10 \mathrm{~m}$ away in the vertical and $2.5-10 \mathrm{~km}$ in the horizontal. If the depth interval is smaller, grid points are weighted more heavily by lateral data, which striates water properties across Denmark Strait.

\subsubsection{Interpolating in Density}

Since water tends to flow along isopycnals, hydrographic features in Denmark Strait are typically distributed along density surfaces. Consequently, interpolating hydrographic data along isopycnals connects these features more effectively than interpolating along lines of constant depth. After interpolating in density space, gridded hydrographic fields are transformed into depth space in order to plot vertical sections. The specific gridding process is as follows: data are first interpolated in both density and depth space onto grids with the same horizontal resolution. Then, each column of data is linearly interpolated to assign depths to gridded values of temperature, salinity, and density that are interpolated in density space. More specifically, these depths are computed by interpolating density onto depth-interpolated grids. Finally, hydrographic fields interpolated in density space are re-interpolated in depth space in order to create grids that are evenly spaced in the vertical.

The spacing between between grid points in density space is $0.01 \mathrm{~kg} / \mathrm{m}^{3}$. Density increases approximately $0.002 \mathrm{~kg} / \mathrm{m}^{3}$ with every $1 \mathrm{~m}-2 \mathrm{~m}$ increase with depth, so this choice in vertical grid spacing matches the vertical grid spacing in depth. 


\subsubsection{Re-gridding and Smoothing}

For analysis purposes, each gridded, synoptic section must have the same resolution. Consequently, data originally interpolated onto the low-resolution grid are re-interpolated onto the medium-resolution grid. Then, all medium-resolution sections are re-interpolated onto the high-resolution grid. Density is also smoothed using an alternating, in-place 1 point Laplacian algorithm. Temperature and salinity, however, are not smoothed in order to preserve the complex features that appear in these hydrographic fields across Denmark Strait. The smoothing algorithm is applied twice after all sections are interpolated onto their initial grids. Furthermore, this smoothing process is repeated every time a section is re-interpolated onto a higher resolution grid. Original data are also reinserted into the density grids after they are transformed into depth space and before they are re-interpolated in depth space. This step is required, since large features that are homogeneous in density are small in density space and therefore tend to be averaged out in the interpolation process. Reinserting data ensures that these features appear in the final, gridded sections.

\subsubsection{Hybrid Gridding Scheme}

Interpolating in density rather than depth coordinates, however, does not always yield an accurate distribution of water properties near the surface. Consequently, occupations are not purely gridded in density space. Instead, the sections are gridded in depth space near the surface $($ sigma $\leq 27.5)$ and in density space near the bottom (sigma $\geq 27.7$ ). The 27.7 isopycnal is chosen as the upper bound for density space interpolation, because it lies above the overflow (27.8). Consequently, this choice ensures that the entire overflow layer is interpolated purely in depth or density space. In order to prevent discontinuities in the hydrography between these two gridded products, another isopycnal is chosen as the lower bound for depth space interpolation. Sigma 27.5 is chosen because it typically falls below the stratified surface layer of Denmark Strait, and it is located sufficiently above the 27.7 isopycnal. Density and depth grids are then averaged (linearly weighted) in the region between the two isopycnals to prevent discontinuities in water properties. Thirty occupations are interpolated entirely in depth space, since features in the trough are averaged out in density space (even when original data are reinserted into the gridded product). 


\subsection{Defining Boluses of Overflow Water in Synoptic Sections}

Boluses are objectively identified in the synoptic sections occupied across Denmark Strait according to their homogeneity in water properties and their size. Weakly stratified overflow water with $N^{2}$ values less than or equal to $2 \times 10^{-6}$ are first identified in gridded $N^{2}$ and density fields. Data points meeting this criterion are assigned 1, and the rest are assigned 0. To create smooth boundaries that isolate these lenses of homogeneous overflow, the matrices of 0 's and 1's are then smoothed using a 2D filter that replaces each element with the mean of the surrounding data points in a $5 \times 5$ grid centered on that element. Boluses must also meet minimum size criteria. Within the lower trough, boluses are required to extend at least 150 meters above sill depth (650 meters). Furthermore, boluses are required to occupy at least $65 \%$ of the lower trough. These size criteria were developed in part to comply with the Spall and Price (1998) modeling study of DSOW, which describes boluses as 150-200 m tall and $30 \mathrm{~km}$ wide. The width of the lower trough is approximately $26 \mathrm{~km}$. The number of boluses in the synoptic sections are not overly sensitive to these size constraints. 


\section{Chapter 3}

\section{Results}

\subsection{Mean State of Denmark Strait}

Individual vertical sections reveal the highly variable nature of the water masses passing through Denmark Strait. By contrast, the mean temperature, salinity, density, and $N^{2}$ sections tell a simpler and arguably richer story. Despite the highly variable distribution of water properties in Denmark Strait, the mean picture captures distinct features that are associated with regional currents. In turn, these features reveal information about the mean locations and velocity structures of the currents. The mean state of Denmark Strait will be addressed as follows. First, the slopes of the isopycnals and their dynamical ramifications will be discussed. Then, each water mass will be identified and related to the deduced currents passing through the strait. Finally, the properties and distribution of DSOW will be described.

Via thermal wind, changes in isopycnal slopes likely indicate the locations of the currents flowing through Denmark Strait. Two such changes occur at the Greenland and Iceland shelf breaks which reveal the mean locations of the shelfbreak and separated EGC, respectively. The isopycnals diverge at the Greenland shelf break (Figure B-8). On the Greenland shelf, the isopycnals are flat, but offshore of the self break, the isopycnals $>27.5$ slope down while the isopycnals $\leq 27.5$ slope up. Although no velocity data are used in this study, other studies of the current system in Denmark Strait suggest these isopycnals are indicative of a surface intensified southward flow overlying a bottom intensified southward flow (Våge, 2013). This trend continues into the trough, and the deep sloping isopycnals steepen beyond the ledge at $130 \mathrm{~km}$ until they reach the Iceland shelf. This steepening is suggestive of 
another surface intensified jet offshore of the Iceland shelf. Furthermore, the slope of the 27.6 isopycnal changes its sign at the Iceland shelf break. The isopycnal slopes down offshore of the shelf break, but slopes up on the Iceland shelf. Since the NIIC is known to flow northward in Denmark Strait, the upward sloping isopycnals suggest that the NIIC is bottom intensified. Consequently, the Iceland shelf break and the strongly sloping isopycnals found there mark the NIIC front in the mean. Additionally the 26.5 isopycnal outcrops at the Greenland shelf break and the 27.25 isopycnal also outcrops at the Iceland shelf break.

Irminger water and polar surface water appear in the mean sections (Figure B-8). Irminger water is the warmest and saltiest water observed in Denmark Strait and is found primarily on the Iceland shelf within the NIIC. Some Irminger water, however, is observed on the Greenland shelf, approximately $150 \mathrm{~m}$ below the surface. This water is colder and fresher than the water on the Iceland shelf. These observations suggest that this water branches from the NIIC north of the Látrabjarg line and returns to Denmark Strait in the southward flowing EGC. However, it is possible that this water separates from the NIIC downstream of the sill and flows northward through Denmark Strait. Above the remnant Irminger water water is cold, fresh polar surface water that is located in the shelf break EGC pathway. As seen in the mean density and $N^{2}$ sections, the polar surface water is highly stratified and contributes the lightest water to the Denmark Strait. However, while the surface water has consistently low salinities in the mean along the entire Greenland shelf, the coldest surface water resides immediately shoreward of the shelf break. Cold and fresh water also appears to penetrate downward and eastward at the shelf break. Only trace amounts of return Atlantic water are found in individual sections, which suggests that this water mixes with surrounding water upstream of Denmark Strait. As a result, this water mass is not detectable in the mean. The coldest water in Denmark Strait resides in the lower trough and will be described in further detail in the following sections.

Consistent with previous studies (Dickson and Brown, 1994; Jonsson, 1999; Jochumsen, 2012), no seasonality in temperature and salinity of Denmark Strait is observed.

\subsection{Synoptic Variability of Denmark Strait}

The most striking variability in synoptic sections of the Látrabjarg line occurs in the trough and is attributable to the passage of boluses of overflow water. As such, this thesis primarily 
focuses on investigating the nature of the boluses. Bolus size, location, hydrography, and frequency of appearance in synoptic sections will first be characterized. Then, the relationship between boluses and changes in the surrounding hydrographic structure of Denmark Strait will be examined. Finally, an estimate for the transport of the overflow water by boluses will be presented.

\subsubsection{Characterizing Denmark Strait Boluses}

Boluses markedly contribute to the variability of Denmark Strait's hydrographic structure, because they are intermittently present and vary in their location, size, and hydrography. Consequently, these three properties of boluses - location, size, and hydrography - will now be described.

Boluses are present in $41 \%$ (46 of the 111) of the synoptic sections, and when they are, they mostly reside in the lower part of the trough, below $500 \mathrm{~m}$ (Figure B-9). The majority of boluses are banked on the western side of the strait, which is consistent with hydraulic theory (Pratt and Whitehead, 2008), but some are found on the eastern side of the trough. This tendency to be banked on the west means that many boluses also tend to occupy the ledge $(100-130 \mathrm{~km})$ and extend furthest into the water column west of the deepest point in the trough (around $130 \mathrm{~km}$ ). The offset between the top of the bolus and the bottom of the trough is also visible in the composite bolus temperature, salinity, and density sections (Figure B-8).

Boluses are the densest, coldest, and saltiest constituents of DSOW and appear as distinct features in synoptic sections (Table A.2). Since boluses consistently occupy a small region of Denmark Strait, they are also strikingly visible in composite bolus sections. Notably, they appear in the composite potential temperature section as a cold lens of water, with temperatures below those observed in the background mean (Figure B-10). In particular, water colder than $0^{\circ} \mathrm{C}$ is observed in the composite bolus temperature section but not in the mean background temperature section. Their presence in the composite salinity section is subtler; they are characterized by a nearly homogeneous salinity field in the trough (below $400 \mathrm{~m}$ ) and a doming of the 34.85 isohaline at $130 \mathrm{~km}$ (Figure B-11). This doming parallels the doming of the deep isopycnals (Figure B-8).

Boluses also have an average cross sectional area of $3.86 \pm 0.24 \mathrm{~km}^{2}$. This value, however, underestimates their true size, because some sections stop short of fully resolving them. 


\subsubsection{Boluses and the Hydrographic Structure of Denmark Strait}

Boluses accompany changes in the overall hydrographic structure of Denmark Strait. In particular, they are associated with shifts in the locations and properties of currents. These changes can be seen in the composite bolus and background states and are highlighted in anomaly sections (composite bolus sections with the background state removed). Adjustments to the hydrographic structure are discussed below in detail.

First, the composite and anomaly sections suggest that the presence of boluses coincides with an eastward shift in the NIIC. As discussed in the section describing the mean state of Denmark Strait, the western front of the NIIC is characterized by strong horizontal density gradients and steeply sloping isopycnals at $150 \mathrm{~km}$ (Figure B-8). Water on the western side of the front (below $150 \mathrm{~m}$ ) is denser than water on the eastern side. Consequently a large, positive density anomaly at $150 \mathrm{~km}$ (and below $150 \mathrm{~m}$ ) suggests that, in the presence of boluses, dense water penetrates regions of Denmark Strait that are otherwise occupied by light Irminger water (Figure B-12). A negative density anomaly, on the other hand, would signify a westward shift in the NIIC.

A similar pattern appears in the temperature anomaly section, which is consistent with this interpretation (Figure B-10). The NIIC contains the warmest water in Denmark Strait, so a negative temperature anomaly at the NIIC front suggests that it shifts eastward in the presence of boluses. It is interesting to note that these density and temperature anomalies (caused by the shift in the NIIC) overwhelm the cold, dense bolus anomalies at the bottom of the trough. On the other hand, the positive salinity anomaly at the bottom of the trough is not masked by the shift in the NIIC. Instead, both the negative anomaly that is associated with the NIIC shift and the positive anomaly that is associated with boluses are present (Figure B-11). Both features show up in the salinity anomaly section since each has anomalies of opposite sign.

Additionally, a region of anomalously high stratification (around $150 \mathrm{~km}$ and $400 \mathrm{~m}$ ) is adjacent to the anomalously low region occupied by boluses (Figure B-13). This dipole pattern suggests an eastward shift in the NIIC.

Second, boluses coincide with a warming and salinificaiton of the Irminger water inflow although the latter signal is less robust (Figure B-10, B-11). A decrease in density on the Iceland shelf is also observed, which is consistent with this warming (Figure B-12). This 
density decrease, however, is partially explained by the eastward shift of the NIIC. Since the isopycnals slope upward (towards Iceland) on the Iceland shelf, an eastward shift in the NIIC would result in a negative vertical displacement of the isopycnals and lead to an overall decrease in density in this region.

Third, the surface water west of the Iceland shelf break (above $100 \mathrm{~m}$ ) is cooler, fresher, lighter, and more stratified in the presence of boluses (Figure B-10, Figure B-11, Figure B-12, Figure B-13). These observations suggest that the passage of boluses coincides with either an increased presence of polar surface water (PSW) or a freshening and cooling of PSW. This PSW signal extends out to $150 \mathrm{~km}$, which corresponds to the mean location of the separated EGC. PSW is also observed in the mean temperature and salinity sections of Denmark Strait (Figure B-8).

\subsubsection{Isopycnal Heaving and Transport}

The results presented here indicate that boluses increase the cross sectional area of the overflow layer at the Látrabjarg line, and may in turn increase the southward transport of DSOW over the sill. The results also suggest that boluses coincide with a depression of isopycnals in the NIIC. These observations will now be described in detail and the boluses' contribution to the transport of overflow water will be estimated.

When boluses pass through Denmark Strait, the deep isopycnals are lifted up towards the surface (Figure B-14). This lifting occurs everywhere west of the Iceland shelf break, below $150 \mathrm{~m}$. Furthermore, isopycnals are displaced upward as much as 150 at the very bottom of the trough, in the region occupied by boluses. Since this displacement coincides with the location of boluses, it is not surprising that magnitude of this displacement matches the minimum height requirement for boluses (as discussed in the data and methods section).

Isopycnal heaving thickens the overflow layer, which leads to an estimated increase in transport of $0.88 \pm 0.29 \mathrm{~Sv}$. This value only represents the contribution from the increase in DSOW thickness. In other words, the contribution from the differences in the advective speed in the presence of boluses is ignored. Furthermore, two important simplifications/assumptions are made. First, DSOW on the Greenland shelf $(<100 \mathrm{~km})$ is excluded from the calculation because of the limited number of observations on the Greenland shelf, none of which sampled it entirely. Second, since there are no concurrent velocity data, a constant advective speed of $0.2 \mathrm{~m} / \mathrm{s}$ was assumed, which is representative of the overflow 
(Våge et al., 2011). Previous studies, however, suggest that boluses are associated with anomalously large velocities (Smith, 1976). Because of these two simplifications, this estimate of the transport difference is likely an underestimate of the true value. The results from this calculation are shown in Table A.2.

Isopycnals are also displaced downward in the NIIC and in the upper $100 \mathrm{~m}$ of Denmark Strait. This picture is consistent with the modifications of the currents described in the previous section.

\subsection{Volumetric T/S Modes and the Origin of Bolus Water}

\subsubsection{Features Seen in Volumetric T/S Plots}

A volumetric T/S plot was constructed using all of the CTD cast measurements in order to investigate the water masses and mixing in Denmark Strait (Figure B-15). The plot reveals that there are two regions of $\mathrm{T} / \mathrm{S}$ space that contain a large percentage of data. These regions are called modes and they are centered on $35.2 \mathrm{psu} / 6^{\circ} \mathrm{C}$ and $34.9 \mathrm{psu} /-0.5^{\circ} \mathrm{C}$. The first represents Irminger Water carried northward in the NIIC, and the second represents a constituent of the overflow that is nearly homogeneous in temperature and salinity. The large fraction of water situated along the 26.7 and 27.7 isopycnals also suggests that mixing occurs along these density surfaces. Additionally, Figure B-15 highlights a tail of cold water that extends from the overflow mode to regions of $\mathrm{T} / \mathrm{S}$ space occupied by fresh, buoyant water (less than $0^{\circ} \mathrm{C}$ and $34 \mathrm{psu}$ ) known as polar surface water. This tail suggests that diapycnal mixing of these two waters occurs.

\subsubsection{Comparison of Mode and Bolus Water in Denmark Strait}

The existence of the overflow mode indicates that a large quantity of DSOW occupies a narrow range of temperatures and salinities. It is therefore likely that most, if not all, of this mode represents boluses. In order to investigate this connection, the structure of the overflow mode in $\mathrm{T} / \mathrm{S}$ space is first inspected in greater detail.

Zooming in on the overflow mode, one sees that the mode consists of a dense core $(<$ 28.03) and a warmer "tail" (Figure B-16). The core is likely comprised of Arctic origin water and will hereafter be referred to as the lower mode. The tail appears to be a mixture of Arctic origin water and another, warmer source water. This other water is likely the return 
Atlantic water. The tail will be referred to as the upper mode.

To evaluate the connection between the overflow modes and boluses, the average temperate and salinity of boluses were compared to the modes. Figure B-16 shows these average temperatures and salinities generally fell within the range of temperatures and salinities of the overflow modes. Furthermore, the locations of the boluses and overflow modes in vertical sections coincide with one another. In particular, upper mode water is primarily found on the ledge (near $130 \mathrm{~km}$ ), lower mode water is primarily in the trough, and bolus water encompasses these two regions (Figures B-9).

Another way to evaluate an overlap in geographic locations is by calculating the percent composition of lower and upper mode water in boluses and vis versa. The calculation reveals that boluses primarily consist of these mode waters and the majority of lower mode water is found in boluses (Figure B-17, Figure B-18). Specifically, the boluses are $48.69 \pm 4.24 \%$ lower mode water and $21.34 \pm 3.43 \%$ upper mode water. Additionally, on average, $71.82 \pm$ $0.28 \%$ of the lower mode water and $28.69 \pm 0.23 \%$ of the upper mode water are contained in a bolus.

\subsubsection{Origin of the Mode Water Upstream of Denmark Strait}

Since boluses mostly consist of upper and lower mode water, the upstream locations of these waters are investigated. In this section, upper and lower mode water will refer to any water having the same temperature and salinity as the upper and lower overflow modes, respectively. Figure B-19 shows the geographic distribution of upper and lower mode water north of Denmark Strait. In these figures, isolated data points corresponding to mode water are filtered out, so only coherent water masses are included in the calculation. Specifically, if more than $20 \%$ of the water 10 meters above or below a data point did not contain the same type of water, the data point is removed from the calculation.

The data suggest that upper mode water is found predominantly in the EGC, since the greatest quantities of upper mode water are found west of the Kolbeinsey ridge. While this water is also found in the Iceland gyre, it is found close to the surface in small quantities. Therefore, it is likely that the upper mode water in the Iceland Sea is quickly transformed during wintertime convection. Consequently, it is unlikely that the upper mode water in Denmark Strait comes from the Iceland Sea.

On the other hand, the lower mode water appears to originate in the Iceland Sea. As 
was the case for the upper mode water, the lower mode water is found relatively close to the surface of the Iceland Sea, but unlike the upper mode water, it is found in large quantities. The lower mode water is also equally close to the surface along the northern portion of the Iceland shelf $(200-300 \mathrm{~m})$. Close to the Látrabjarg line, the top of the lower mode water is found at $350-450 \mathrm{~m}$, or $100-200 \mathrm{~m}$ above sill depth. These observations are consistent with the idea that lower mode water is carried in the NIJ and comprises the lower limb of the Iceland Sea overturning loop (discussed in the introduction). Furthermore, the depth of lower mode water in the vicinity of the sill is consistent with the height of boluses $(\geq 150 \mathrm{~m}$. It should also be noted that a large portion of mode water is present water east of Iceland, near $10^{\circ} \mathrm{W}$ and $65^{\circ} 30^{\prime} \mathrm{N}$. Consequently, some of the lower mode water may originate from this location as well. 


\section{Chapter 4}

\section{Conclusion}

\subsection{Summary}

This study has investigated the hydrographic structure and variability in Denmark Strait using 111 shipboard sections occupied between 1990 and 2012. The mean sections reveal the presences of the of the shelfbreak EGC and the separated EGC in the strait. The sections also show Irminger water on the Iceland shelf and, to a lesser extent, on the Greenland shelf. Polar surface water is present in the mean sections as well, but return Atlantic water is not.

Large, cold lenses of water called boluses are observed in the bottom of the trough in almost half of the sections, and synoptic variability in the hydrographic structure of Denmark Strait is tied to their intermittent presence. Boluses are colder, denser, and saltier than the background overflow water, and they are responsible for variability in the hydrographic properties of DSOW. Furthermore, they are associated with a warming and eastward shift in the NIIC and a freshening and cooling of surface waters west of the Iceland shelf. Boluses also increase the thickness of the overflow water, and as a consequence, they likely increase the southward transport of DSOW at the sill.

Hydrographic data north of Denmark Strait suggest that most of the water contained in boluses comes from the Iceland Sea.This Arctic origin water is primarily found in the lower trough in Denmark Strait. The data also suggest that a smaller, yet substantial, portion of bolus water comes from the EGC. This water is found mostly on the ledge at the sill and is likely a mixture of return Atlantic water and Arctic origin water. 


\subsection{Discussion}

The results also show that the properties and locations of currents and water masses change in Denmark Strait with the passage of boluses. Boluses coincide with a warming and eastward shift of the NIIC. They also coincide with an amplification of the polar surface water, which approaches Denmark Strait in the EGC. This signal extends to $170 \mathrm{~km}$, which is the hypothesized mean location of the separated EGC. More investigation is needed to determine whether this amplification is due to an increased presence of PSW, a freshening and cooling of PSW, or a combination of both. Regardless, these changes in the currents (and the waters advected by them) suggest that the dynamics of all the currents in Denmark Strait - the NIJ, NIIC, shelfbreak EGC, and separated EGC - are linked.

The results presented in this study imply that boluses contribute to the transport of DSOW in several ways. First, boluses are $0.099 \pm 0.004 \mathrm{~kg} / \mathrm{m}^{3}$ denser than the surrounding DSOW. The numerical modeling study of Price and Baringer (1994), which investigated deepwater outflows from marginal seas, found that a larger difference in density between the overflow and overlying water results in stronger entrainment and an increase in transport. The significance of this 0.099 density difference on the transport, however, has yet to be determined.

Second, boluses contribute more than $0.88 \mathrm{~Sv}$ to DSOW at the sill due to the upward heaving of the isopycnals. This displacement in isopycnals increases the cross sectional area of the overflow and, assuming no change in the rate at which DSOW spills over the sill, increases the transport. More hydrographic sections across the entirety of Denmark Strait, however, are needed in order to calculate the total increase in transport (at the sill) due to isopycnal heaving. Velocity measurements of boluses and background DSOW are also needed to calculate the total contribution of boluses to the overflow transport.

Third, the results indicate that boluses are features frequently seen in synoptic sections in Denmark Strait. Due to the lack of continuous, hydrographic measurements across the sill, it is impossible to say whether boluses frequent the sill with any sort of periodicity and, if so, what that period is. It is therefore impossible to draw a connection between the passage of boluses and cyclone genesis. On the other hand, boluses are present in a little under half of the sections, and this observation does not refute the possibility of such a connection. Simultaneous CTD and velocity measurements are needed to answer this 
question. If boluses do spin up cyclones, boluses would play an important role in entraining water and increasing the transport of NADW south of the sill.

$\mathrm{T} / \mathrm{S}$ analysis of DSOW suggests that boluses primarily consist of two different upstream sources. The majority of boluses are associated with lower mode water. The geographic distribution of this water north of Denmark Strait suggests that it originates in the Iceland Sea and approaches the sill in the NIJ. Furthermore, most of the lower mode in Denmark Strait is contained in boluses. For this reason, boluses give us insight into the nature of the NIJ. Some of the boluses include lighter, warmer upper mode water. The location of this water in the vertical sections across Denmark Strait and in the historical, hydrographic dataset of upstream CTD casts suggest that this water is carried southward to the sill in the EGC. 
Appendix A

Tables 
Table A.1: List of the 111 hydrographic occupations of Denmark Strait across the Látrabjarg Line. Part (a) contains identification information for the cruises listed in the "cruise" column of part (b).

\begin{tabular}{ccc} 
Abbreviation & Ship Name & Country \\
\hline A & Árni Friđriksson & Iceland \\
AR & Aranda & Finland \\
B & Bjarni Sæmundsson & Iceland \\
D & Discovery & United Kingdom \\
JR & James Clark Ross & United Kingdom \\
KN & Knorr & United States \\
M & Meteor & Germany \\
MSM & Maria S. Merian & Germany \\
P & Poseidon & Germany \\
PS & Polarstern & Germany
\end{tabular}

(a)

\begin{tabular}{|c|c|c|c|c|c|}
\hline Date & Cruise & Date & Cruise & Date & Cruise \\
\hline March 1990 & B-03-1990 & May 1998 & B-06-1998 & August 2005 & $\mathrm{P}-327$ \\
\hline August 1990 & B-13-1990 & August 1998 & A-09-1998 & August 2005 & P-327 \\
\hline November 1990 & B-17-1990 & September 1998 & B-09-1998 & November 2005 & B-13-2005 \\
\hline February 1991 & B-03-1991 & September 1998 & $\mathrm{P}-244$ & February 2006 & B-02-2006 \\
\hline May 1991 & B-07-1991 & September 1998 & $\mathrm{P}-244$ & May 2006 & B-04-2006 \\
\hline September 1991 & A-12-1991 & September 1998 & P-244 & September 2006 & D-311 \\
\hline November 1991 & B-14-1991 & October 1998 & PS-52 & November 2006 & A-11-2006 \\
\hline February 1992 & B-02-1992 & November 1998 & B-12-1998 & February 2007 & B-03-2007 \\
\hline May 1992 & B-07-1992 & February 1999 & B-02-1999 & May 2007 & B-08-2007 \\
\hline September 1992 & A-08-1992 & May 1999 & B-07-1999 & July 2007 & MSM-05-4 \\
\hline September 1992 & B-14-1992 & August 1999 & A-10-1999 & August 2007 & B-11-2007 \\
\hline October 1992 & B-16-1992 & September 1999 & B-13-1999 & November 2007 & A-14-2007 \\
\hline February 1993 & B-02-2003 & November 1999 & B-16-1999 & February 2008 & A-01-2008 \\
\hline May 1993 & B-07-1993 & February 2000 & B-02-2000 & May 2008 & B-08-2008 \\
\hline August 1993 & A-14-1993 & May 2000 & B-06-2000 & August 2008 & A-11-2008 \\
\hline September 1993 & B-11-1993 & August 2000 & B-10-2000 & October 2008 & KN-194 \\
\hline October 1993 & B-14-1993 & November 2000 & B-14-2000 & November 2008 & A-13-2008 \\
\hline February 1994 & B-03-1994 & February 2001 & B-02-2001 & February 2009 & B-01-2009 \\
\hline May 1994 & B-08-1994 & May 2001 & B-06-2001 & May 2009 & B-05-2009 \\
\hline September 1994 & B-14-1994 & August 2001 & & June 2009 & MSM-12-1 \\
\hline October 1994 & B-17-1994 & November 2001 & B-14-2001 & August 2009 & B-10-2009 \\
\hline March 1995 & B-03-1995 & May 2002 & B-05-2002 & November 2009 & A-14-2009 \\
\hline May 1995 & B-07-1995 & August 2002 & B-09-2002 & February 2010 & B-04-2010 \\
\hline August 1995 & A-11-1995 & September 2002 & P-294 & May 2010 & B-08-2012 \\
\hline September 1995 & B-14-1995 & November 2002 & A-10-2002 & July 2010 & M-82-1 \\
\hline November 1995 & B-17-1995 & February 2003 & A-02-2003 & August 2010 & B-12-2010 \\
\hline February 1996 & B-03-1996 & May 2003 & A-09-2003 & February 2011 & B-01-2011 \\
\hline August 1996 & A-11-1996 & August 2003 & B-03-2003 & May 2011 & B-04-2011 \\
\hline October 1996 & A-14-1996 & September 2003 & P-303 & August 2011 & M-85-2 \\
\hline February 1997 & B-03-1997 & November 2003 & B-10-2003 & August 2011 & KN-203 \\
\hline May 1997 & B-06-1997 & February 2004 & B-01-2004 & December 2011 & B-10-2011 \\
\hline August 1997 & A-14-1997 & May 2004 & B-05-2004 & February 2012 & B-02-2012 \\
\hline August 1997 & AR-34 & November 2004 & B-15-2004 & May 2012 & B-05-2012 \\
\hline September 1997 & AR-34 & February 2005 & B-02-2005 & June 2012 & MSM-21-1b \\
\hline September 1997 & B-10-1997 & May 2005 & B-06-2005 & July 2012 & JR-267 \\
\hline November 1997 & B-15-1997 & August 2005 & A-09-2005 & August 2012 & $\mathrm{P}-437$ \\
\hline February 1998 & B-02-1998 & August 2005 & $\mathrm{P}-327$ & August 2012 & B-09-2012 \\
\hline
\end{tabular}


Table A.2: Mean and standard errors of the potential temperature, salinity, and potential density of boluses and non-bolus overflow. The last column contains transport estimates of the total overflow water (east of the Greenland shelf) in the presence and absence of boluses. Transports were estimated using a constant velocity of $0.2 \mathrm{~m} / \mathrm{s}$, a value characteristic of the overflow (Våge et al., 2011).

\begin{tabular}{lcccc} 
& $\theta\left({ }^{\circ} \mathrm{C}\right)$ & Salinity $(\mathrm{psu})$ & $\sigma \theta\left(\mathrm{kg} / \mathrm{m}^{3}\right)$ & Est. Transport (Sv) \\
\hline Boluses & $-0.087 \pm 0.029$ & $34.993 \pm 0.003$ & $28.031 \pm 0.002$ & $2.862 \pm 0.141$ \\
Background DSOW & $0.806 \pm 0.040$ & $34.853 \pm 0.004$ & $27.931 \pm 0.002$ & $1.984 \pm 0.146$ \\
Difference (Bolus - Background) & $-0.894 \pm 0.069$ & $0.046 \pm 0.007$ & $0.099 \pm 0.004$ & $0.877 \pm 0.287$
\end{tabular}


Appendix B

\section{Figures}




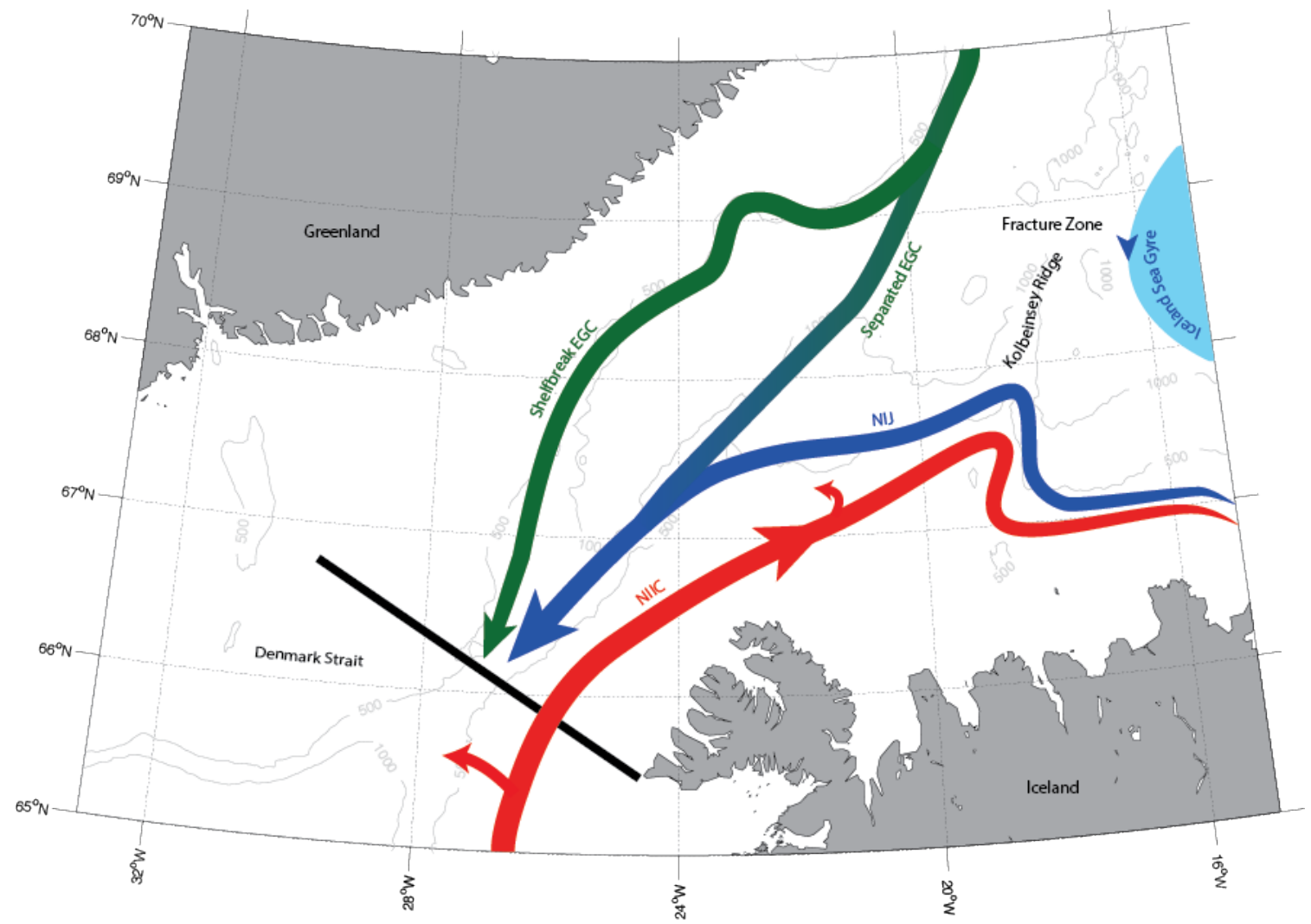

Figure B-1: Schematic of the currents flowing through Denmark Strait. The sill is located at the Látrabjarg line (drawn in black). The $500 \mathrm{~m}$ and $1000 \mathrm{~m}$ isobaths are contoured in grey. 


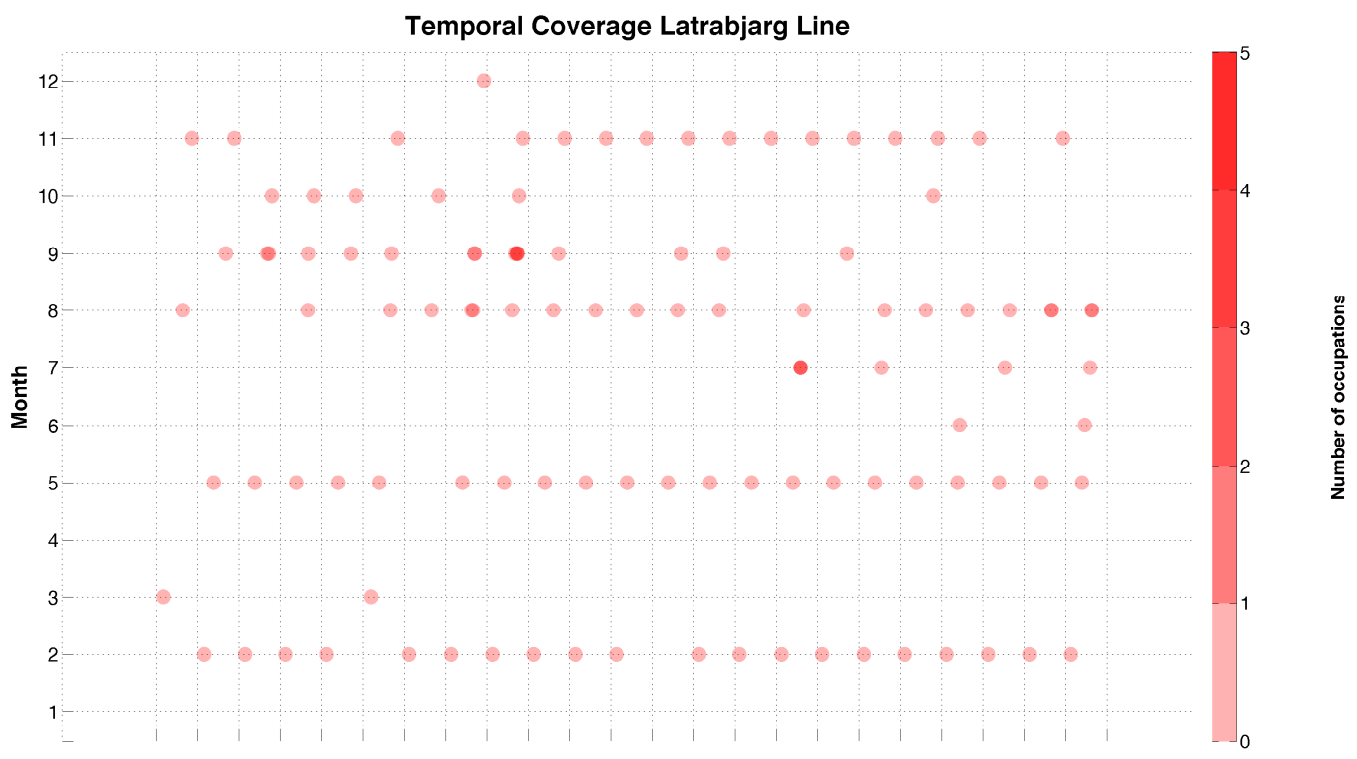

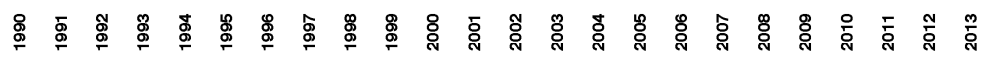

(a)

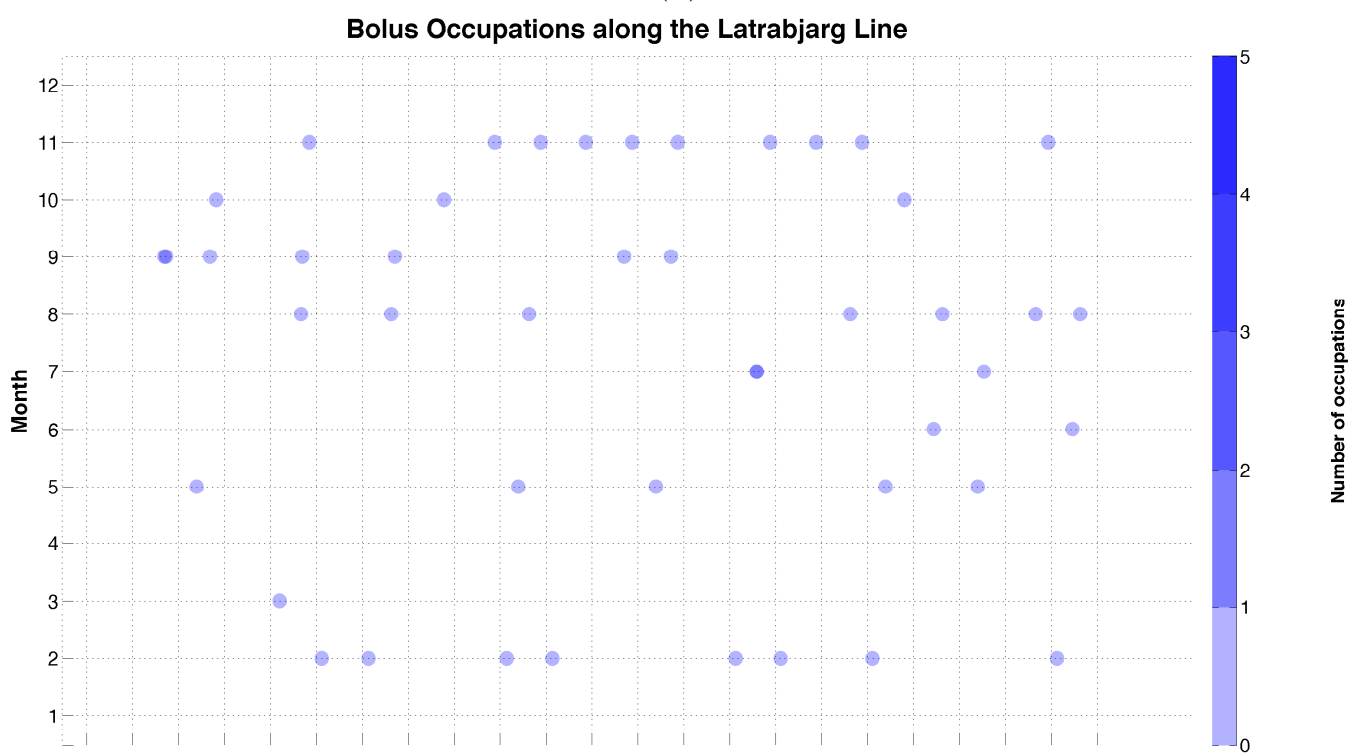

\section{垔}

(b)

Figure B-2: The months and years of all the occupations (a) and the occupations with boluses (b). The marker's opacity indicates the number of occupations conducted in a given month and year. 


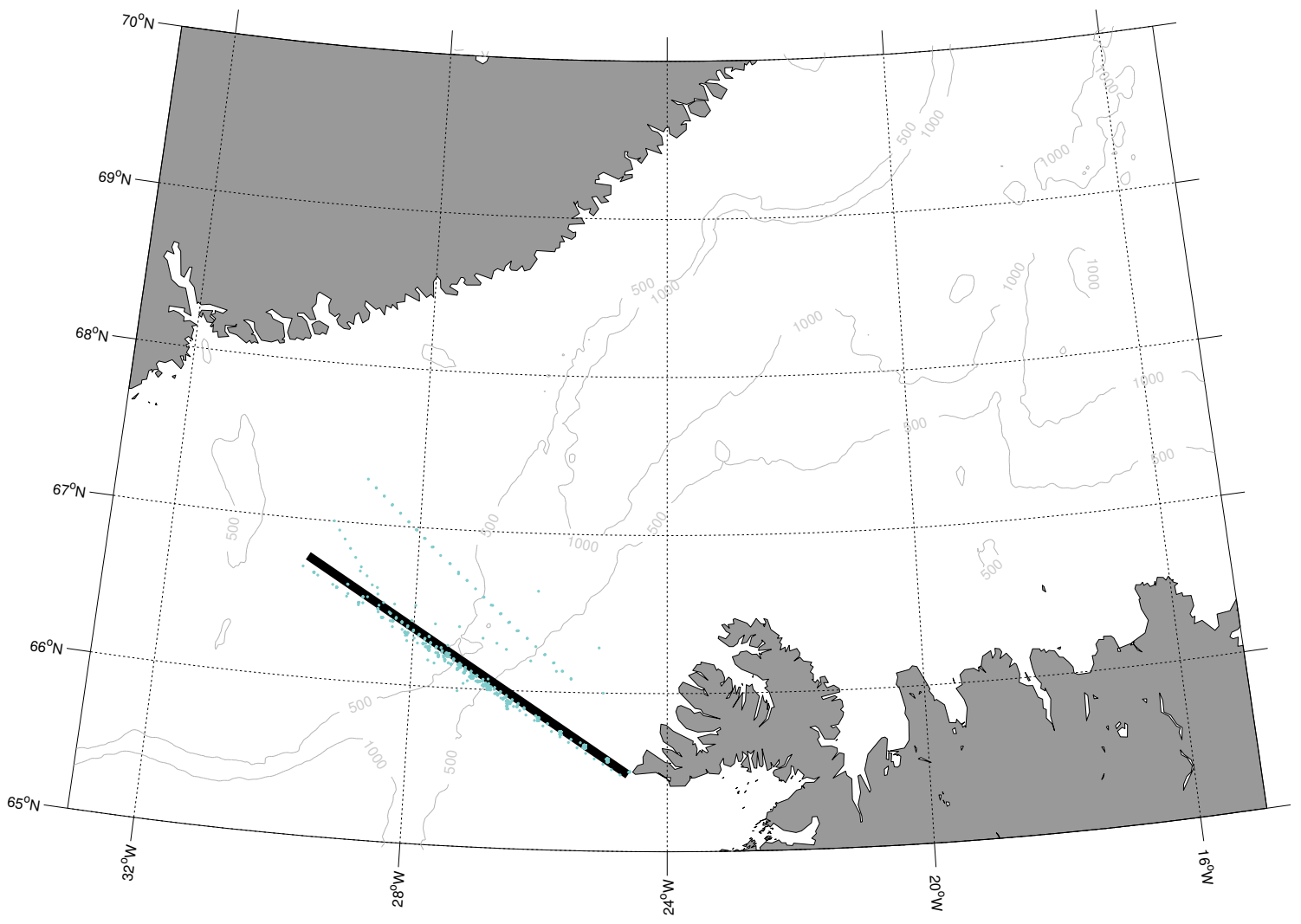

Figure B-3: The Látrabjarg line (draw in black) and CTD stations in green. The CTD stations are from 111 shipboard crossings of Denmark Strait. The $500 \mathrm{~m}$ and $1000 \mathrm{~m}$ isobaths are contoured in grey. 


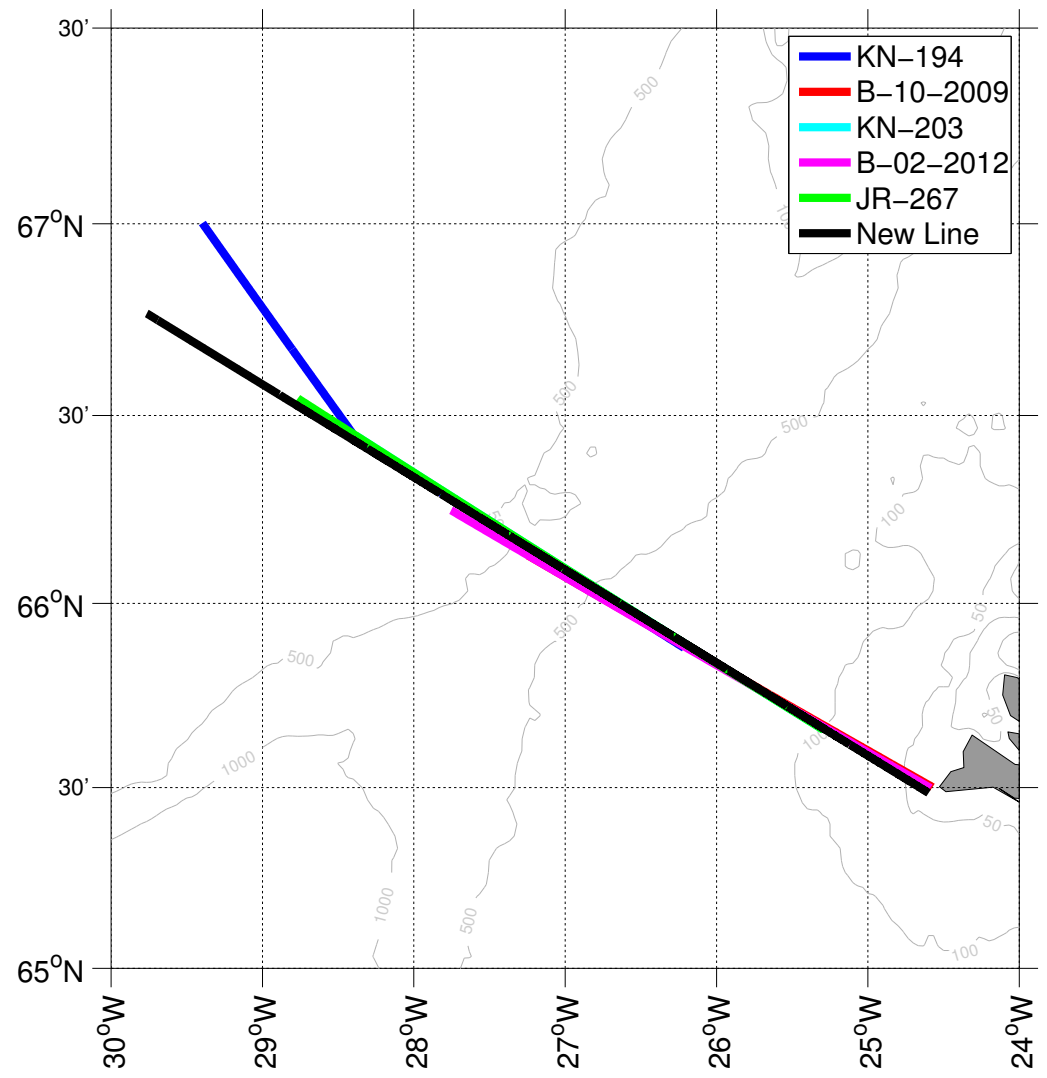

(a)

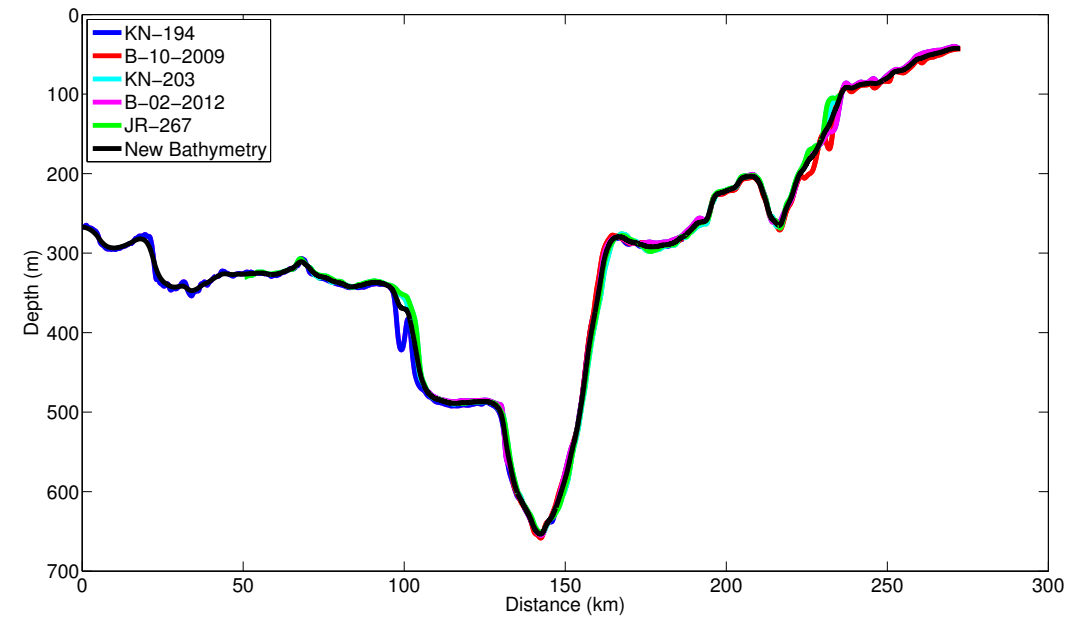

(b)

Figure B-4: The cruise tracks (a) and corresponding echo-sounder measurements (b) from 5 cruises that occupied Denmark Strait. The Látrabjarg line (black) is created from the best-fit line of the cruise tracks. The bend in KN-194 is removed from this calculation. The echo-sounder data are filtered to create the corresponding bathymetric contour in (b). The $500 \mathrm{~m}$ and $1000 \mathrm{~m}$ isobaths are contoured in grey in (a). 


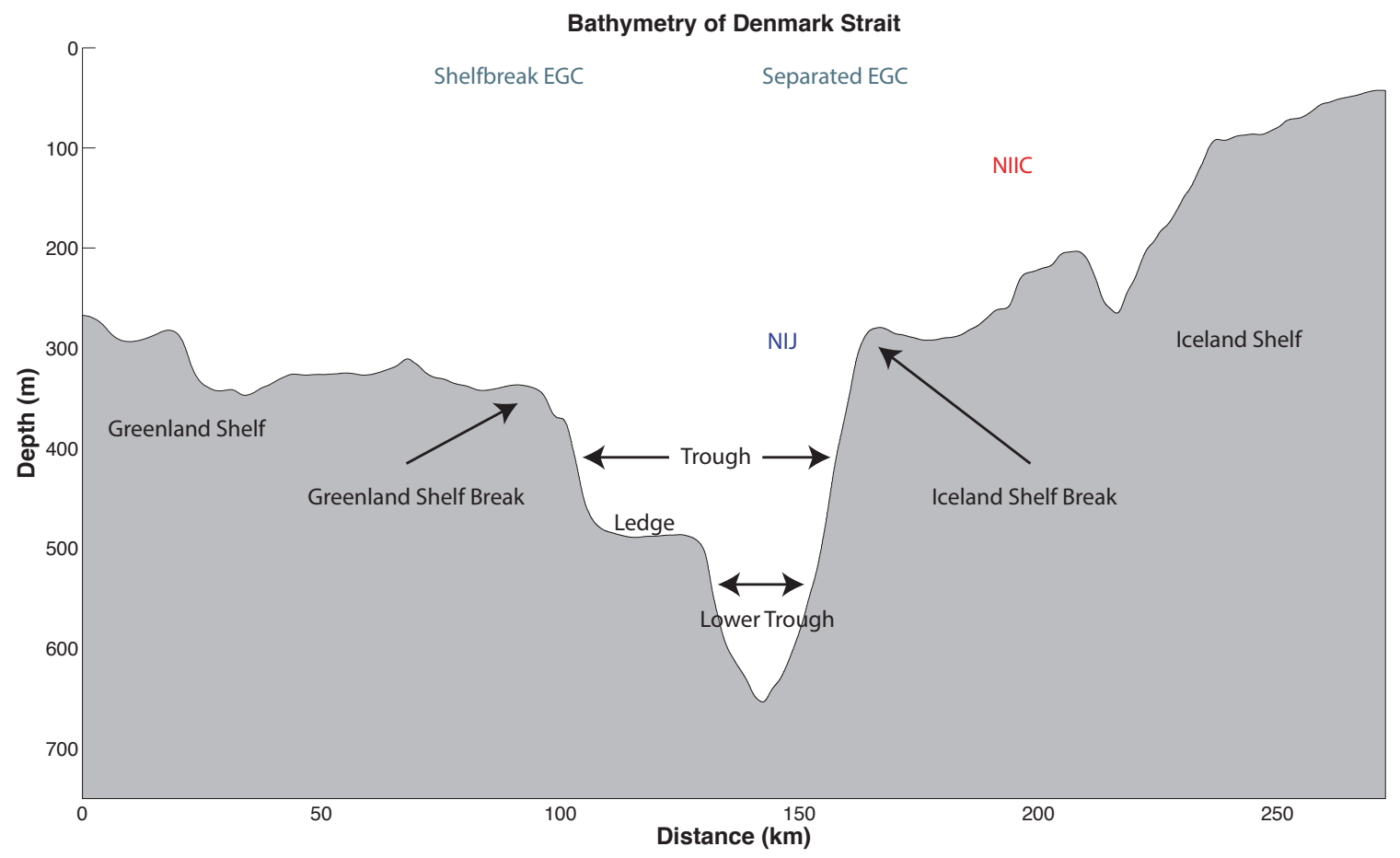

Figure B-5: Locations of bathymetric features in Denmark Strait across the Látrabjarg line. The approximate locations of the currents are labeled in color. The acronyms are EGC $=$ East Greenland Current; NIJ $=$ North Icelandic Jet; NIIC $=$ North Icelandic Irminger Current. 


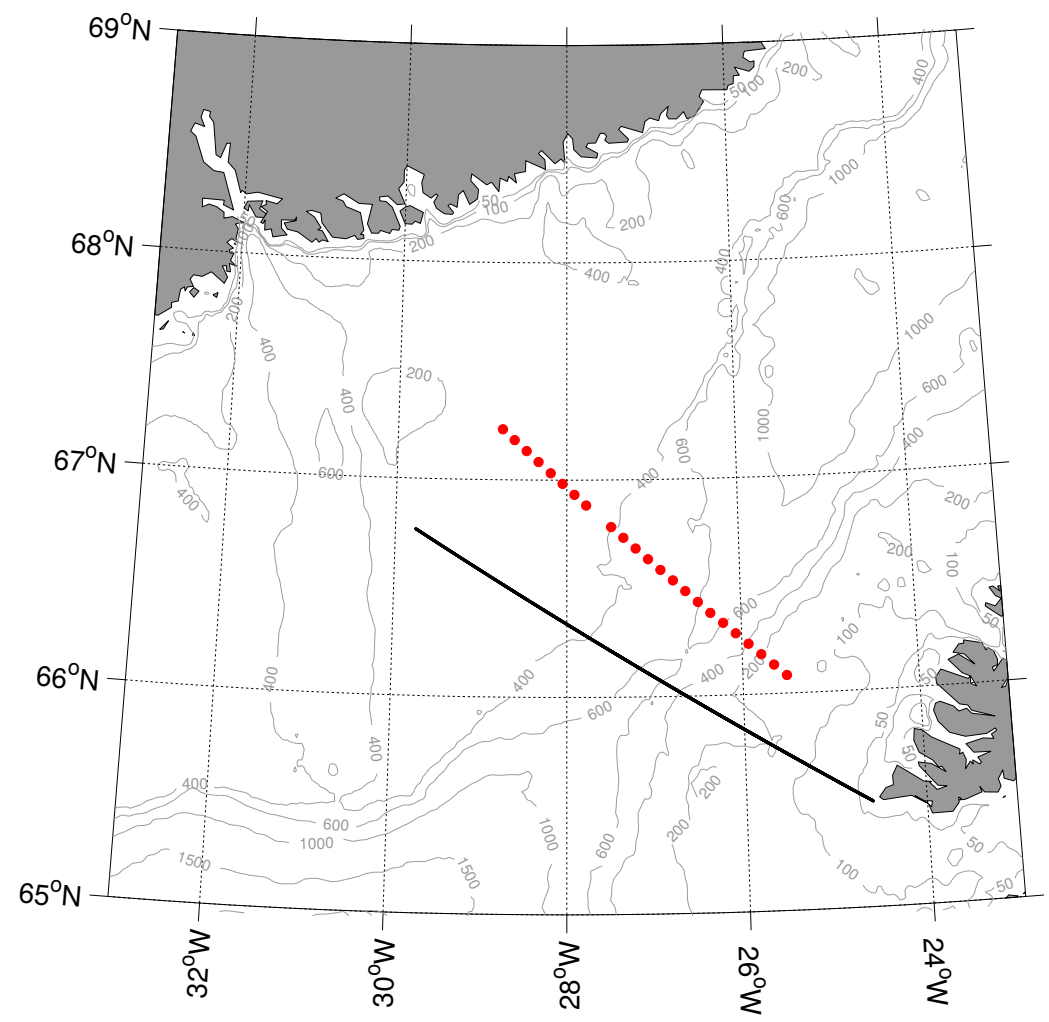

(a)

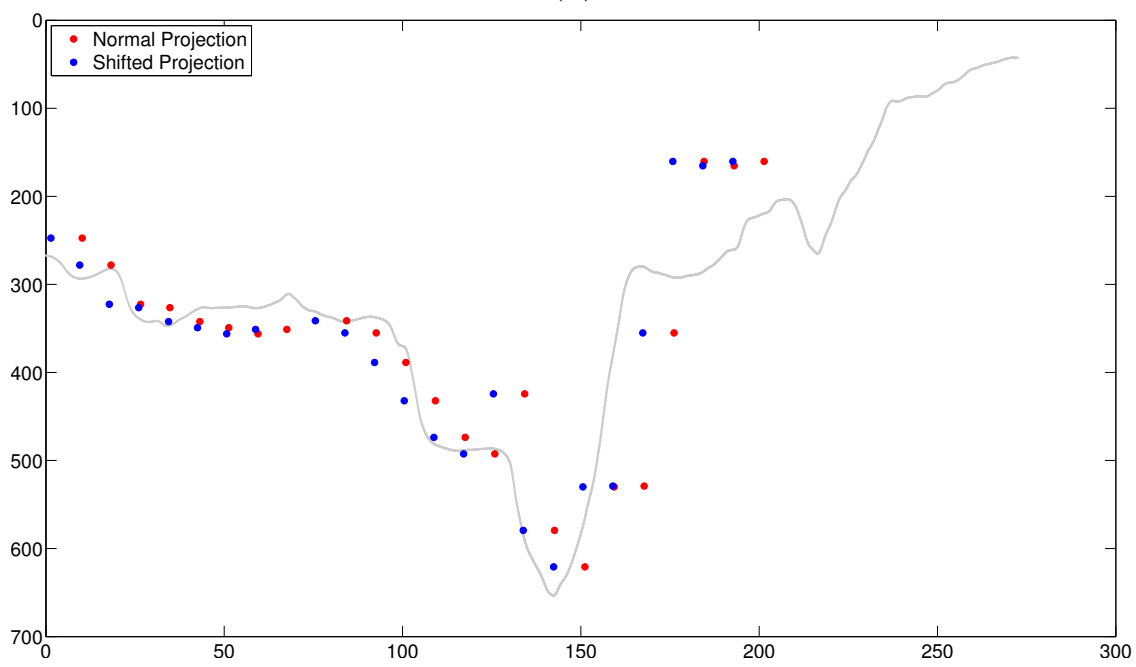

(b)

Figure B-6: Station locations (a) and depths (b) taken on cruise P-294 in the vicinity of the Látrabjarg line. Stations were first projected onto the Látrabjarg line (b, red) and then shifted (b, blue). The bathymetry is contoured in grey. 


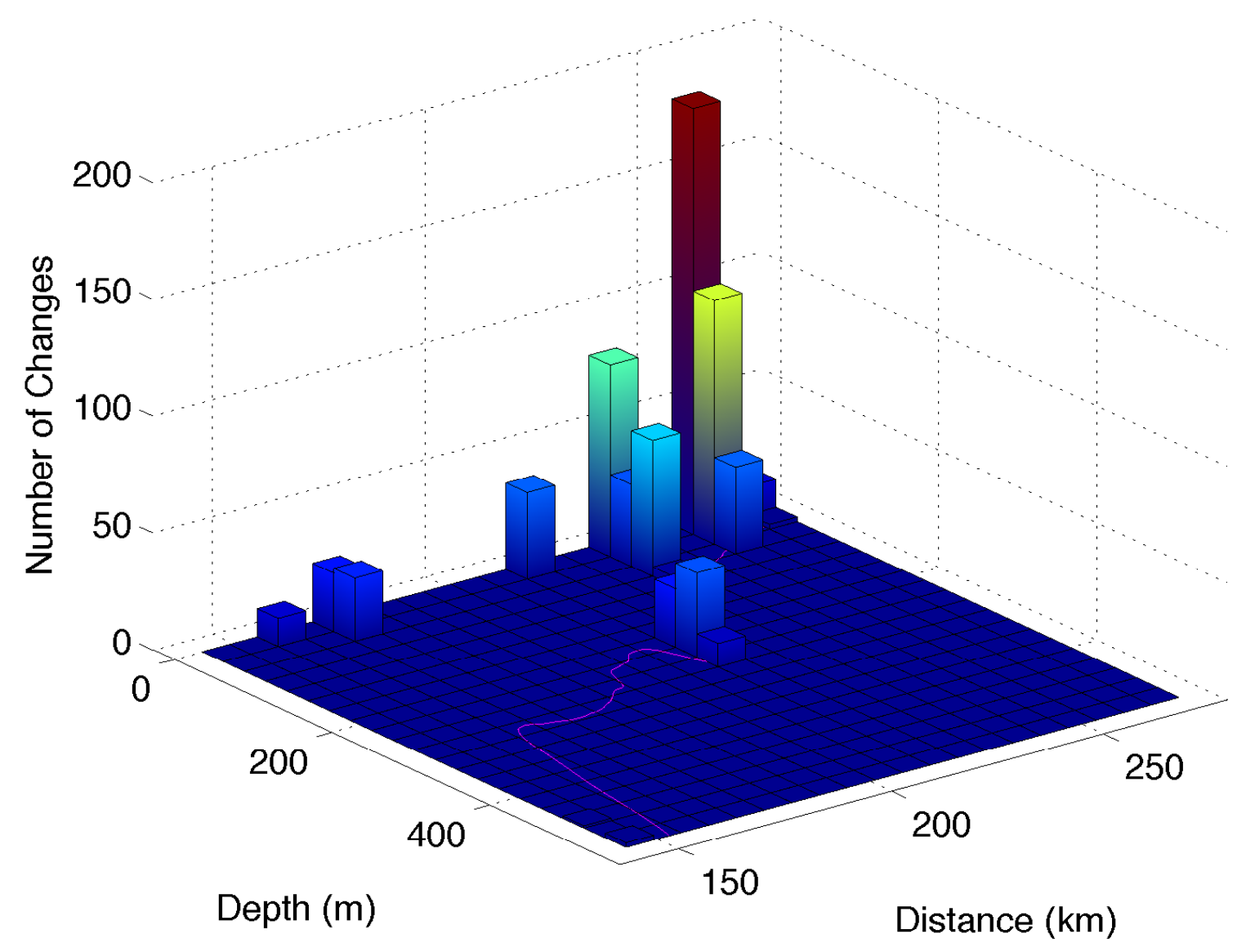

Figure B-7: The number and location (in vertical sections along the Látrabjarg line) of data that are modified to eliminate density inversions. 


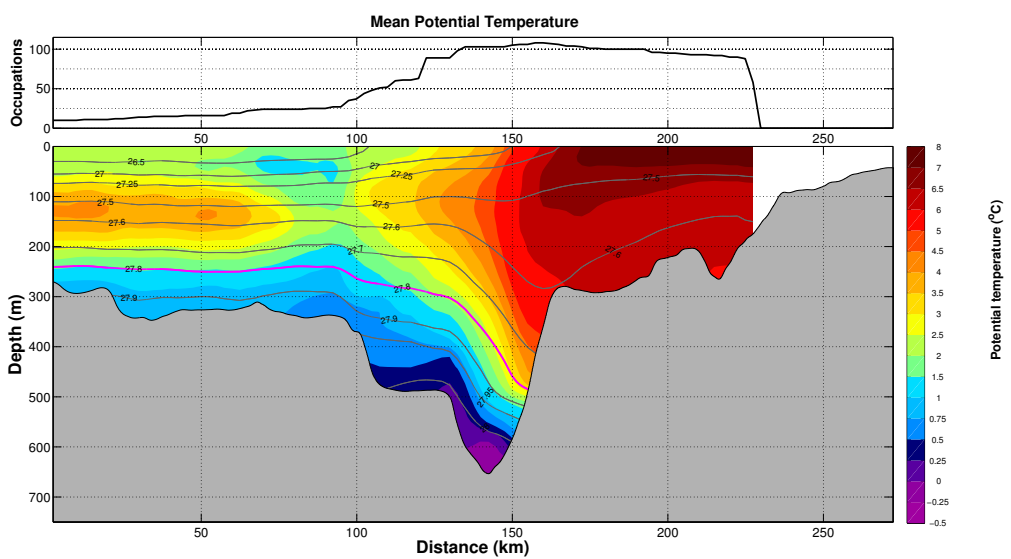

(a)

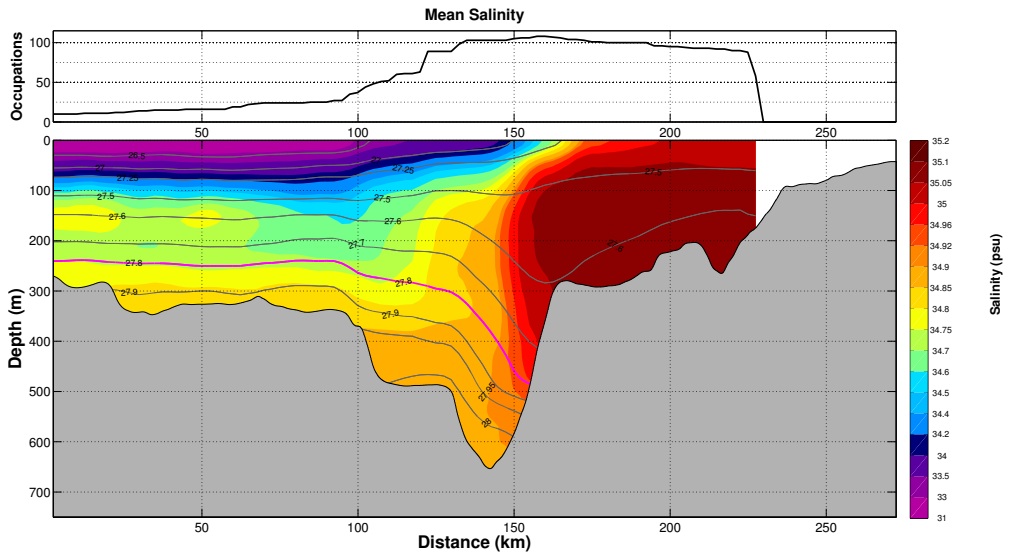

(b)

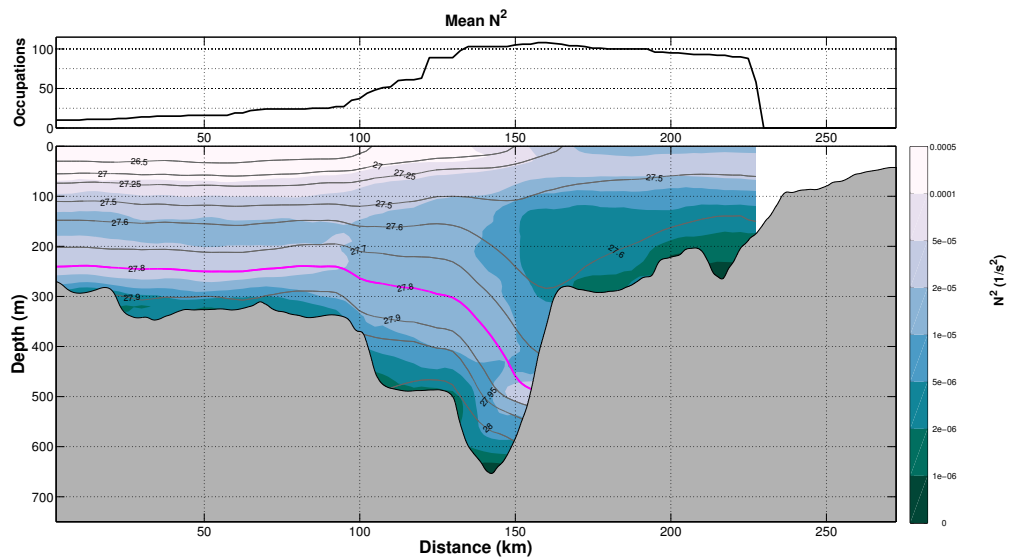

(c)

Figure B-8: The mean potential temperature (a), salinity (b), and $N^{2}$ (c) of the Látrabjarg line. Potential density is contoured in black and the 27.8 isopycnal, which indicates the top of the overflow, is highlighted in pink. The lines above each subplot indicate the number of independent samples across the section. 


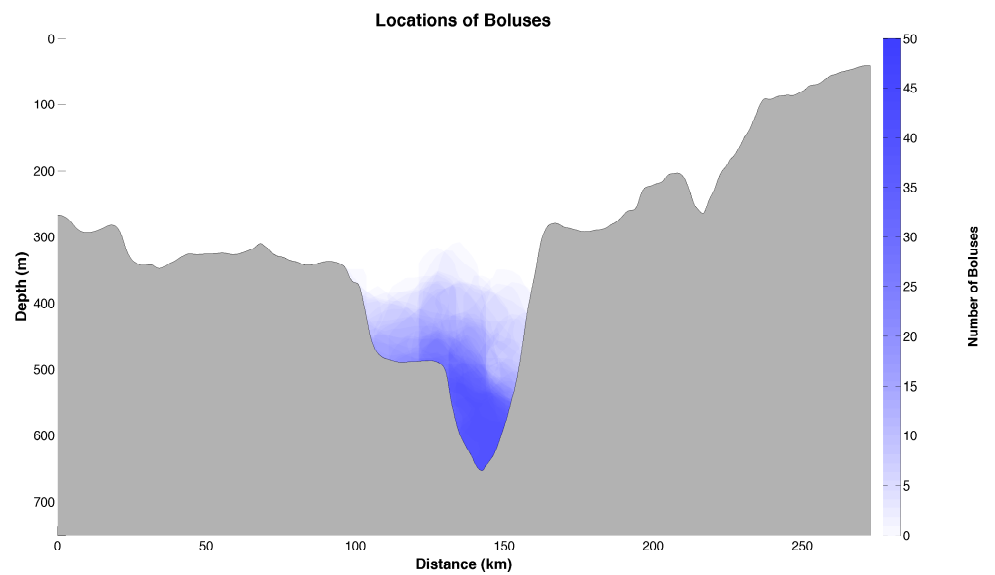

(a)

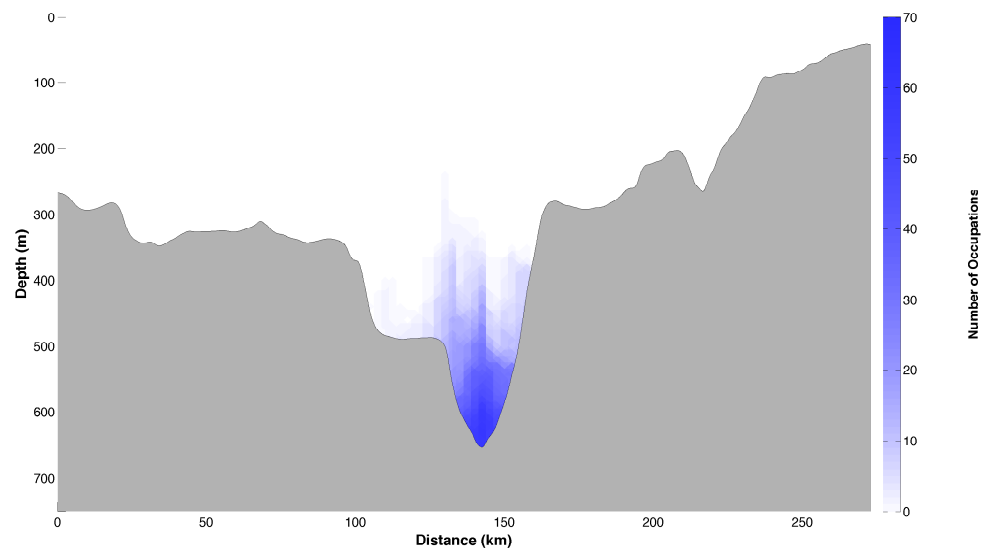

(b)

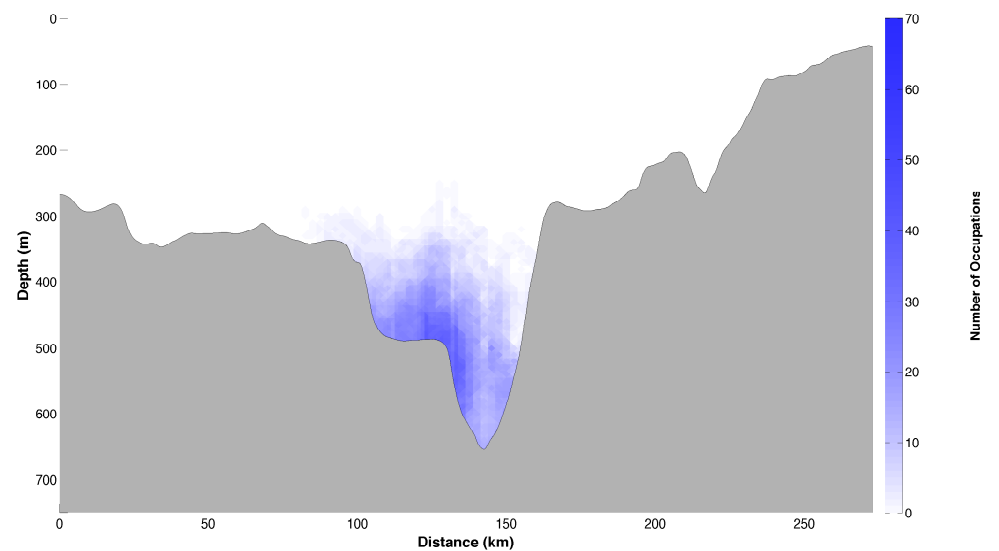

(c)

Figure B-9: Realizations of (a) boluses, (b) lower mode water, and (c) upper mode water identified in synoptic sections across Denmark Strait. 


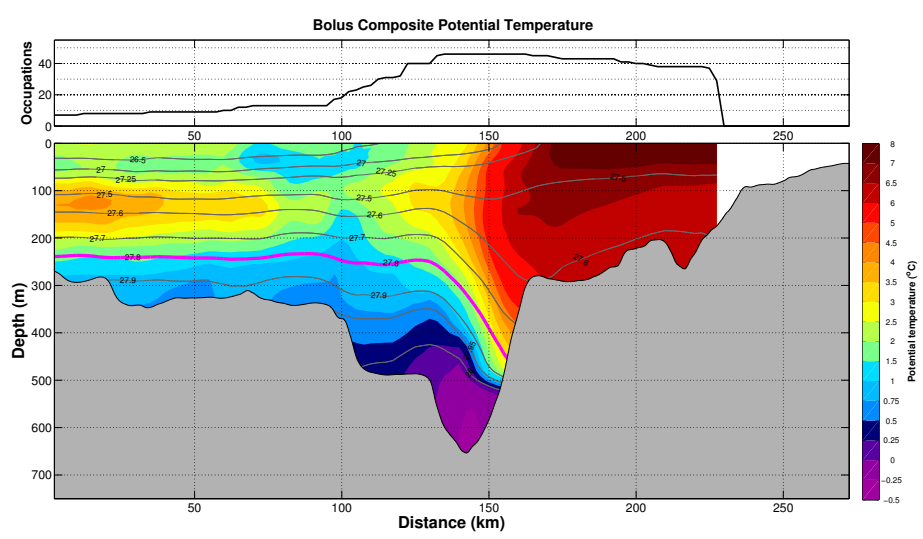

(a)

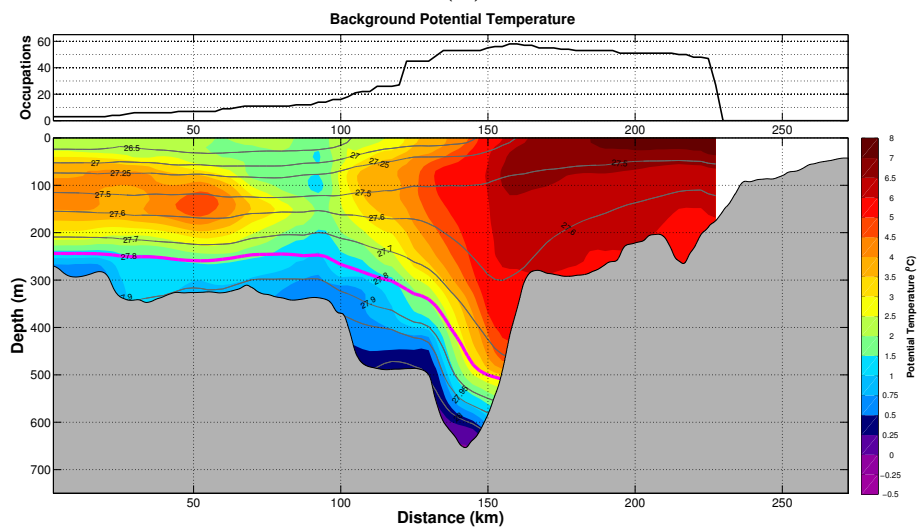

(b)

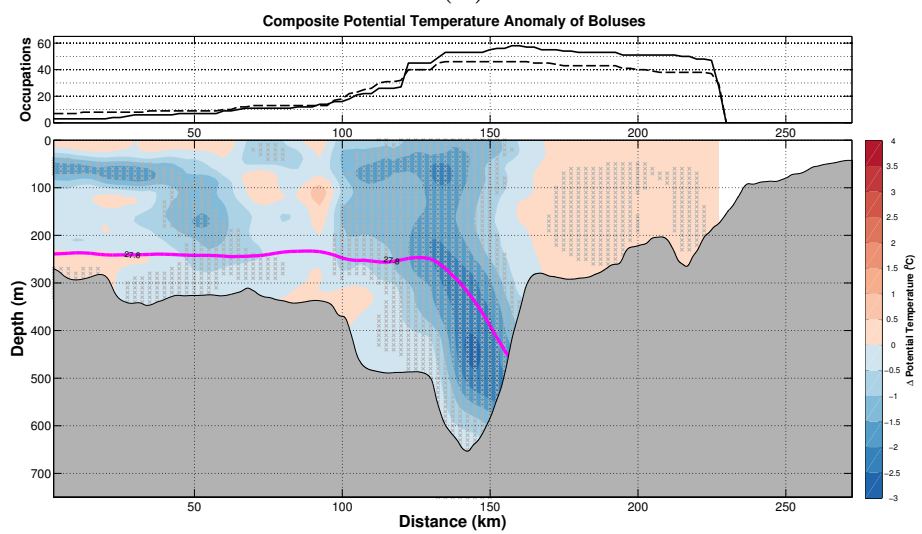

(c)

Figure B-10: The composite bolus (a), background (b), and anomaly (c) sections of potential temperature. Potential density is contoured in black and the 27.8 isopycnal, which indicates the top of the overflow, is highlighted in pink. The lines above each subplot indicate the number of independent samples across the section. In the anomaly subplots, the dashed line represents the number of bolus samples and the solid line represents the number of background samples. The grey crosses indicate regions of the plot where the spread in bolus and background values do not overlap. 


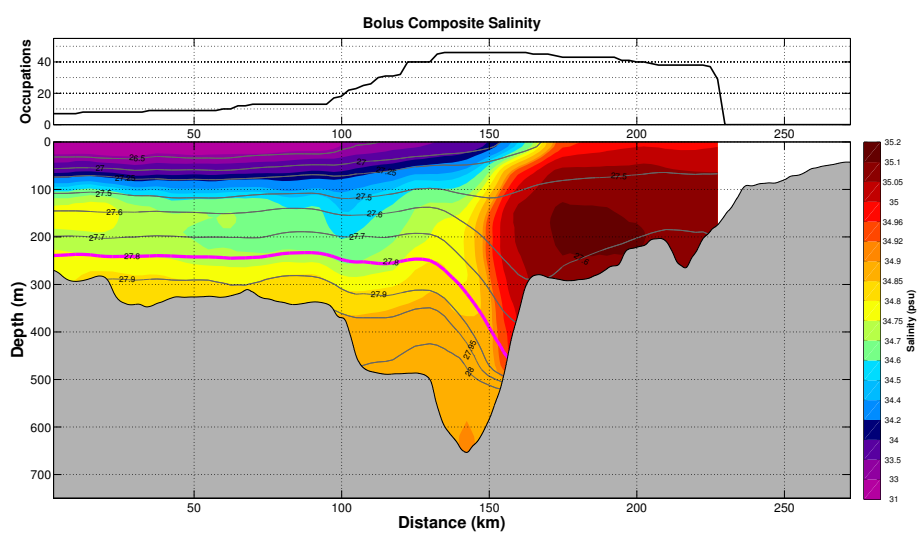

(a)

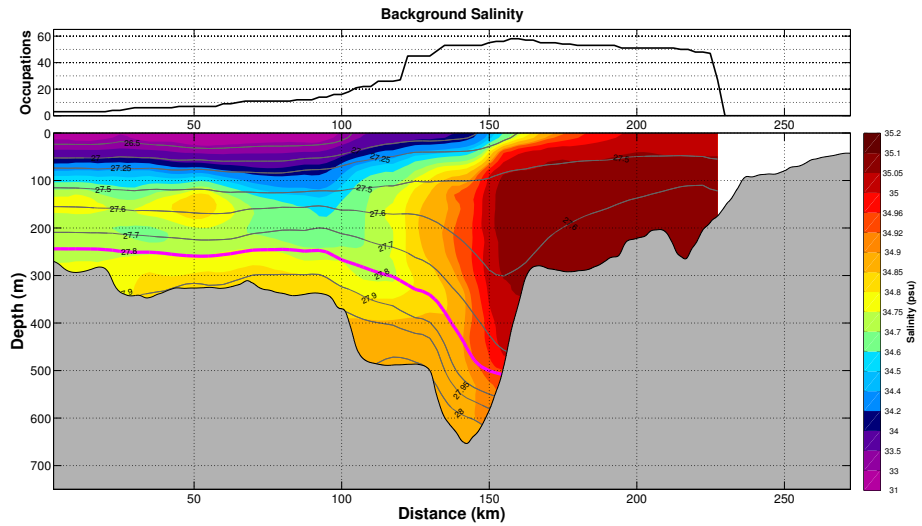

(b)

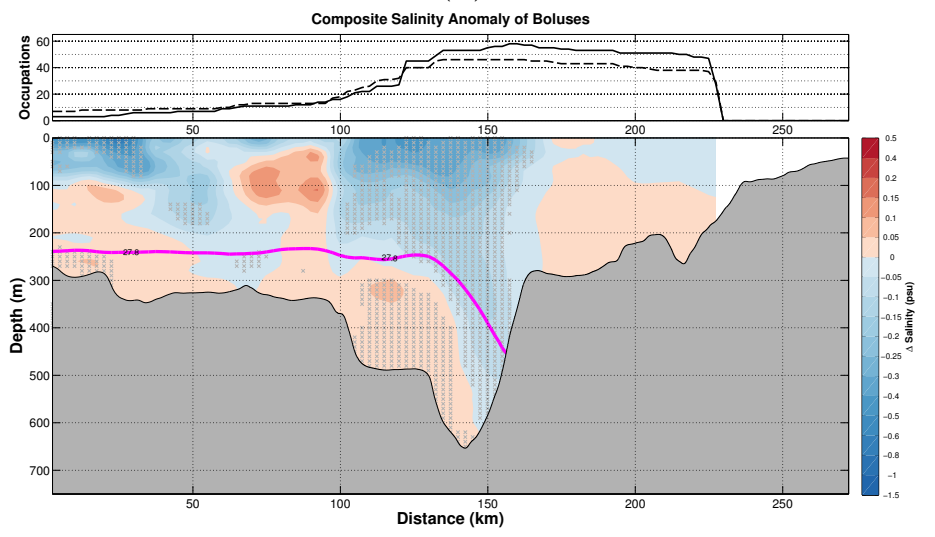

(c)

Figure B-11: The composite bolus (a), background (b), and anomaly (c) sections of salinity. Potential density is contoured in black and the 27.8 isopycnal, which indicates the top of the overflow, is highlighted in pink. The lines above each subplot indicate the number of independent samples across the section. In the anomaly subplots, the dashed line represents the number of bolus samples and the solid line represents the number of background samples. The grey crosses indicate regions of the plot where the spread in bolus and background values do not overlap. 


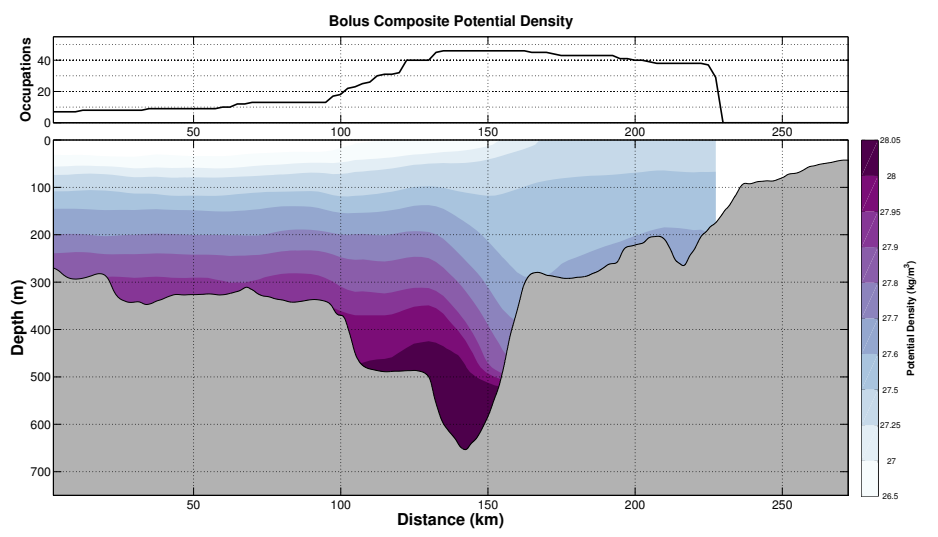

(a)

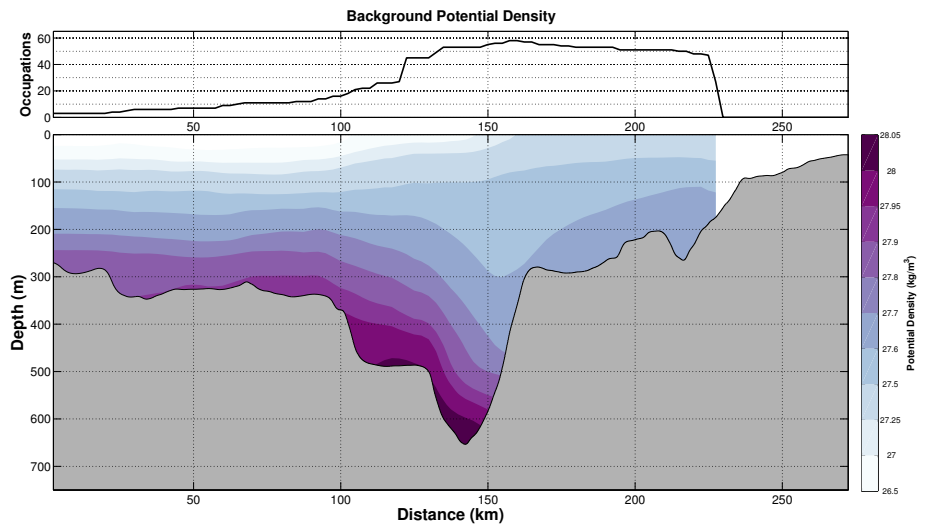

(b)

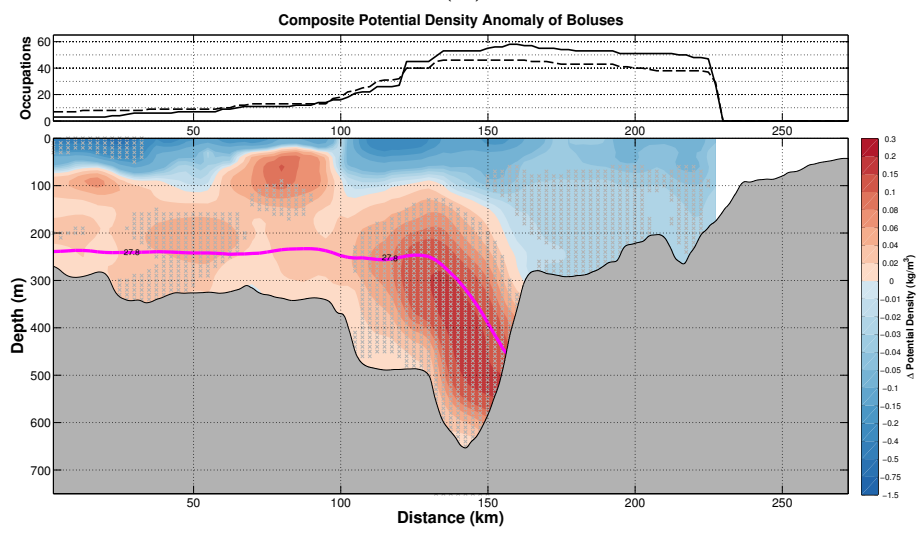

(c)

Figure B-12: The composite bolus (a), background (b), and anomaly (c) sections of potential density. The 27.8 isopycnal, which indicates the top of the overflow, is highlighted in pink. The lines above each subplot indicate the number of independent samples across the section. In the anomaly subplots, the dashed line represents the number of bolus samples and the solid line represents the number of background samples. The grey crosses indicate regions of the plot where the spread in bolus and background values do not overlap. 


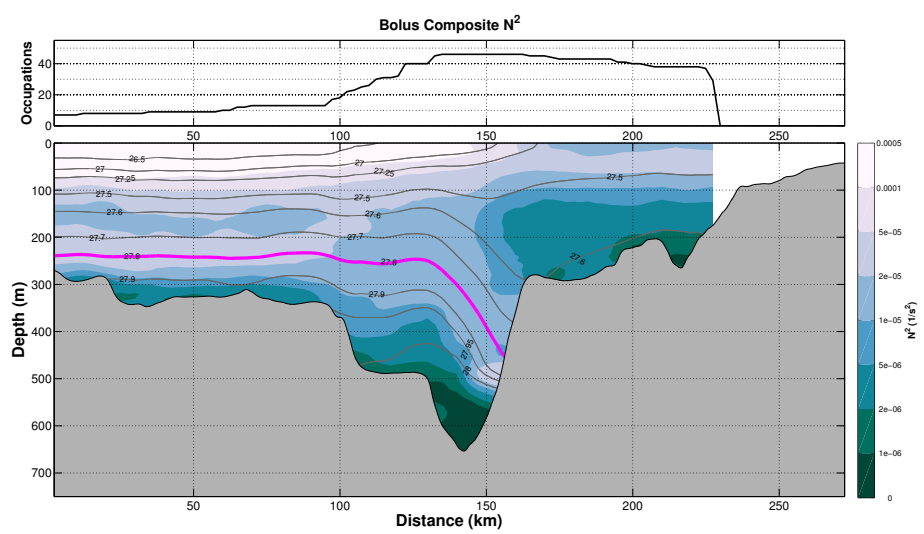

(a)

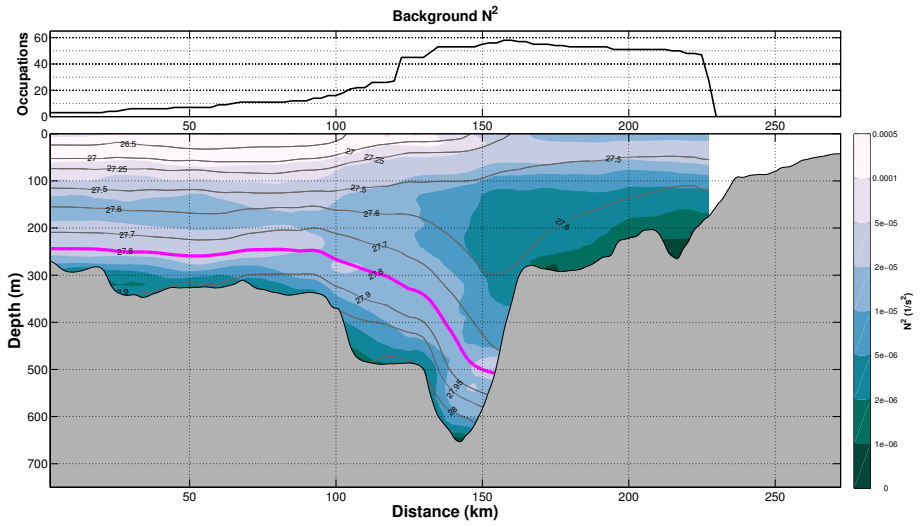

(b)

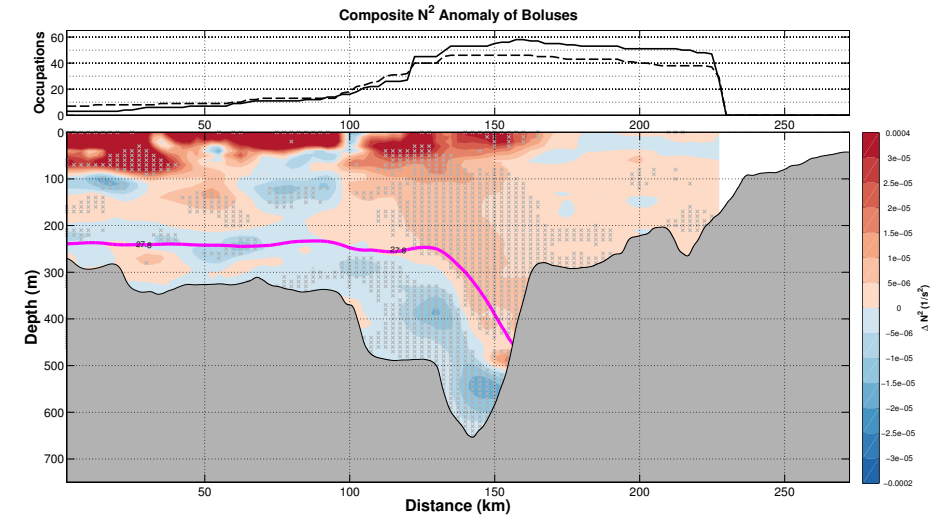

(c)

Figure B-13: The composite bolus (a), background (b), and anomaly (c) sections of $N^{2}$. Potential density is contoured in black and the 27.8 isopycnal, which indicates the top of the overflow, is highlighted in pink. The lines above each subplot indicate the number of independent samples across the section. In the anomaly subplots, the dashed line represents the number of bolus samples and the solid line represents the number of background samples. The grey crosses indicate regions of the plot where the spread in bolus and background values do not overlap. 


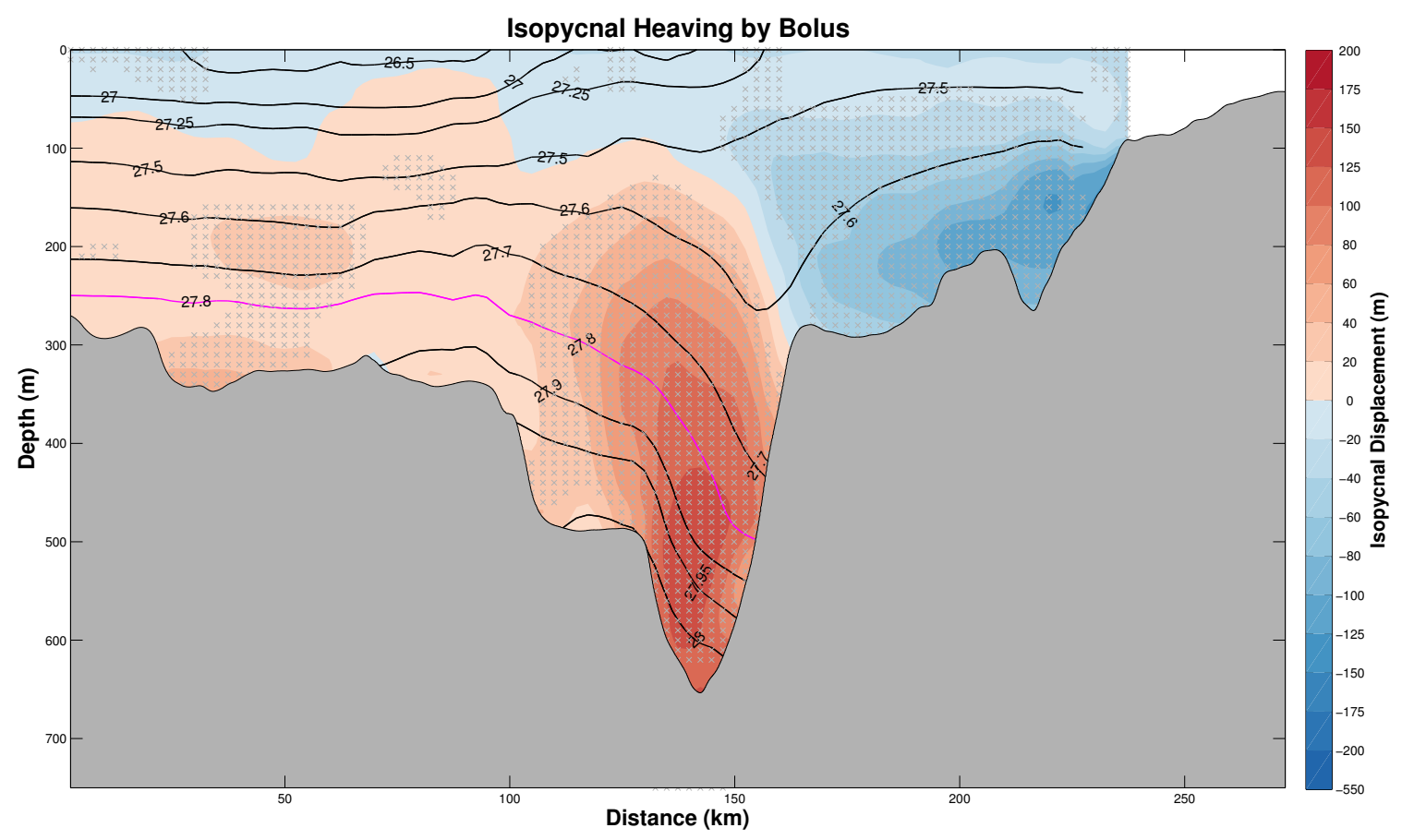

Figure B-14: Mean vertical displacement of the isopycnals in Denmark Strait due to the passage of boluses (color). Overlaid on this is the potential density (contours) of the background state (in the absence of boluses). The grey crosses indicate regions of the plot where the spread in bolus and background values do not overlap.

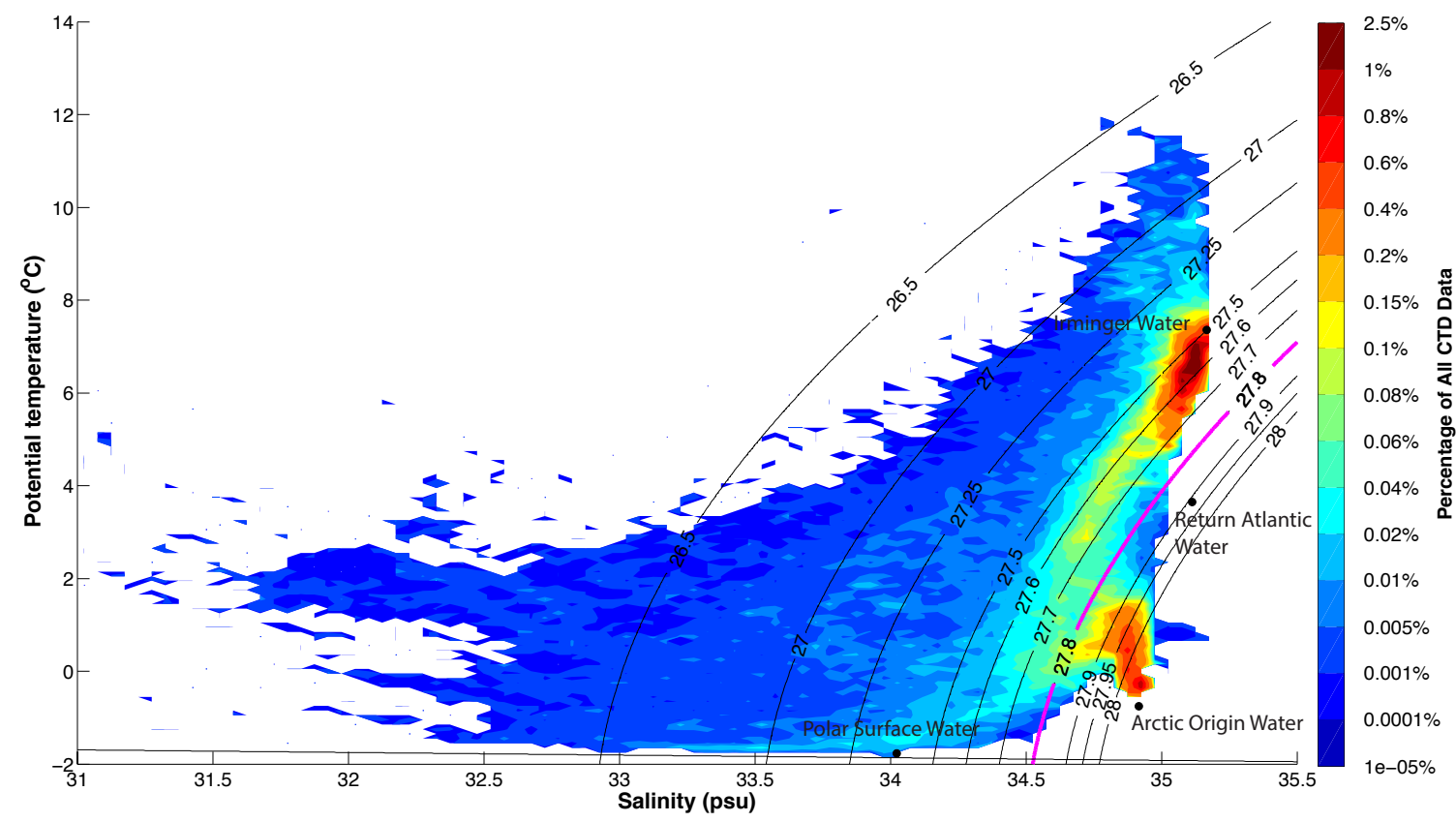

Figure B-15: The volumetric $\mathrm{T} / \mathrm{S}$ plot of all the measurements from all the occupations of the Látrabjarg line. The pink density contour represents the upper, density bound of the overflow. The thermohaline indices of Irminger water, polar surface water, return Atlantic water, and Arctic origin water are indicated by black dots. 


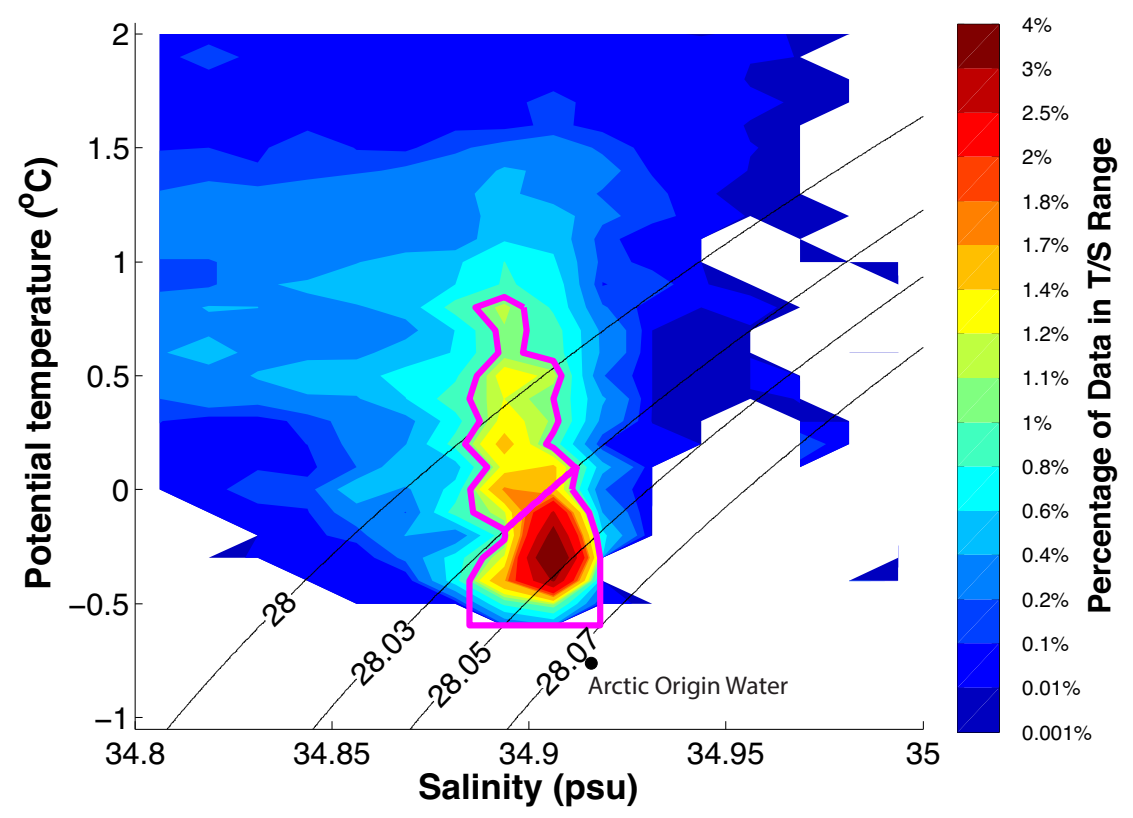

(a)

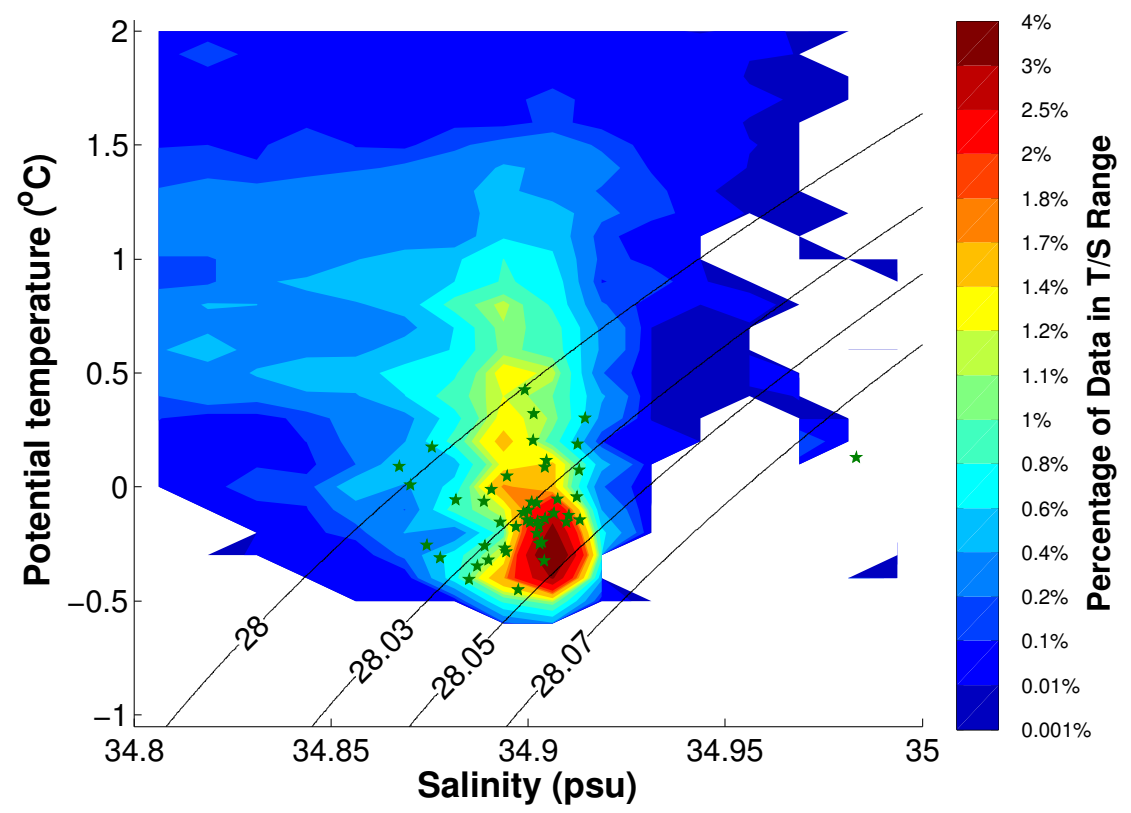

(b)

Figure B-16: The volumetric $\mathrm{T} / \mathrm{S}$ plot of the densest measurements from the Látrabjarg line. In (a) The upper (warmer) and lower (colder) $\mathrm{T} / \mathrm{S}$ modes are outlined in pink. In (b) the mean temperature and salinity of each bolus is indicated by a green star. 


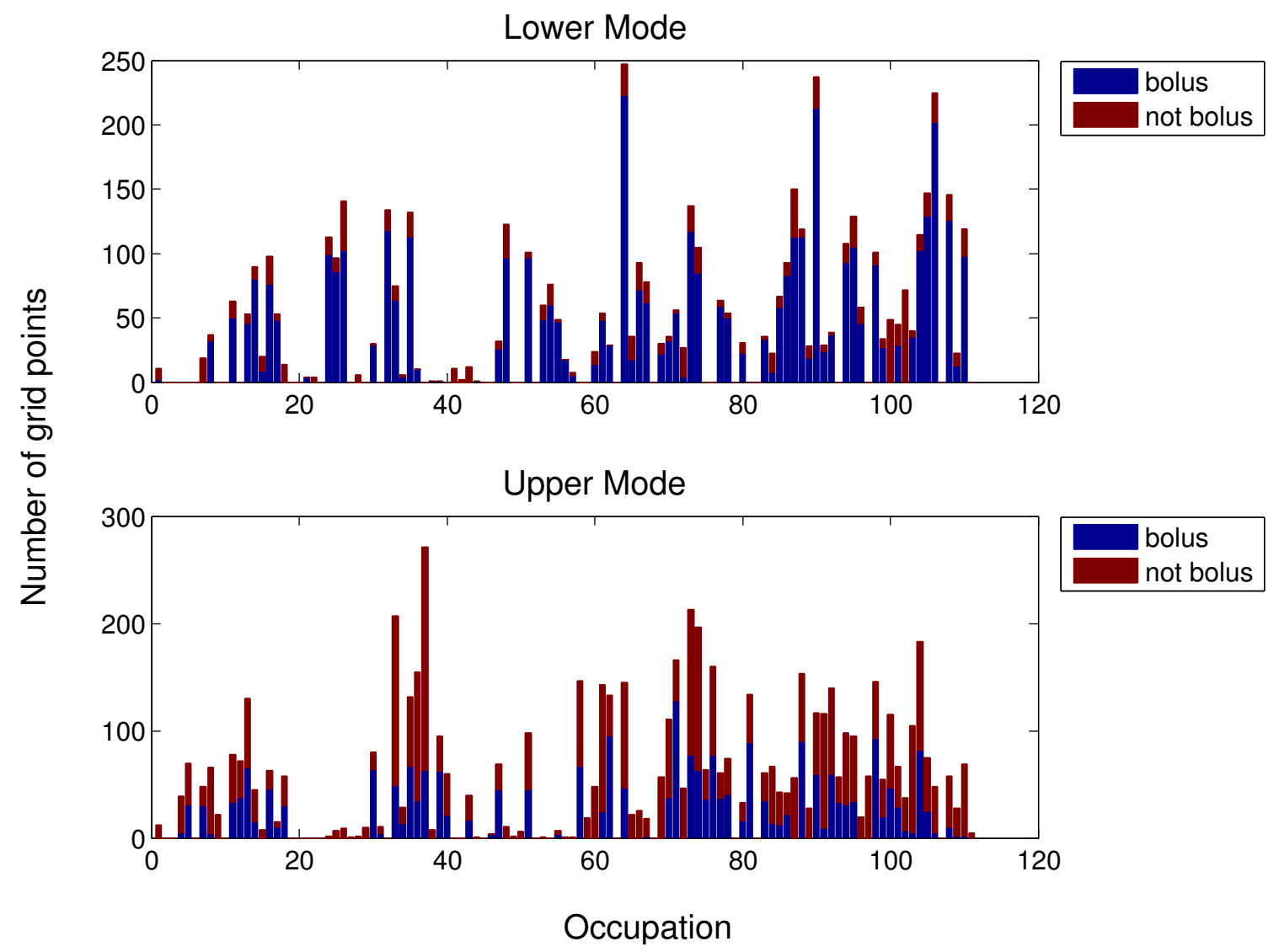

Figure B-17: The number of grid points representing lower mode water (upper subplot) and upper mode water (lower subplot) and whether they are contained in boluses. 


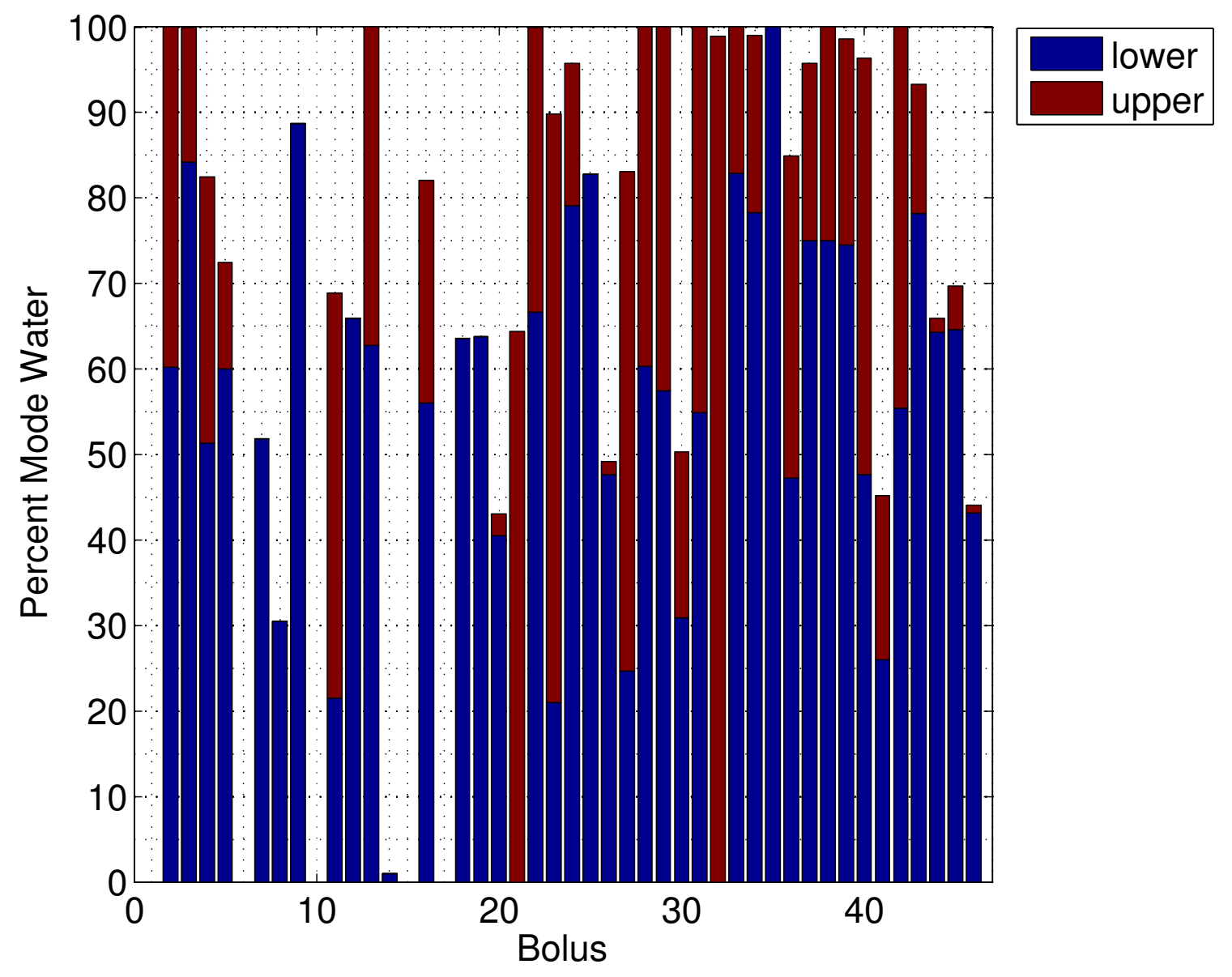

Figure B-18: The percent composition of lower and upper mode water for each of the 46 boluses. 


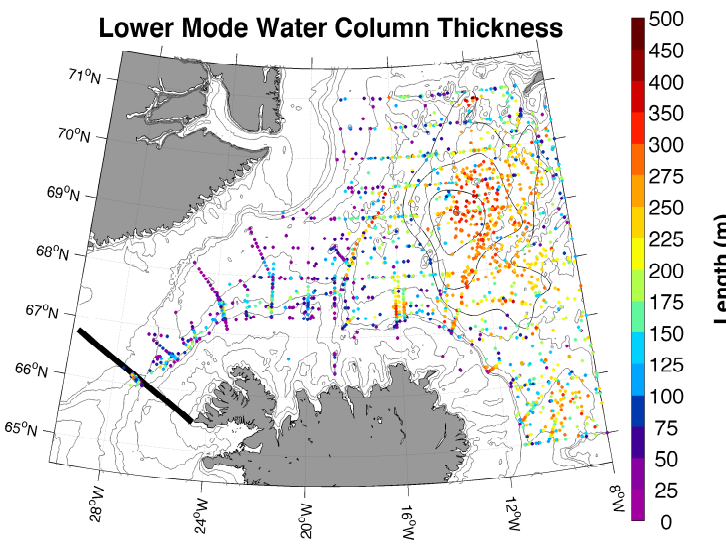

(ai)

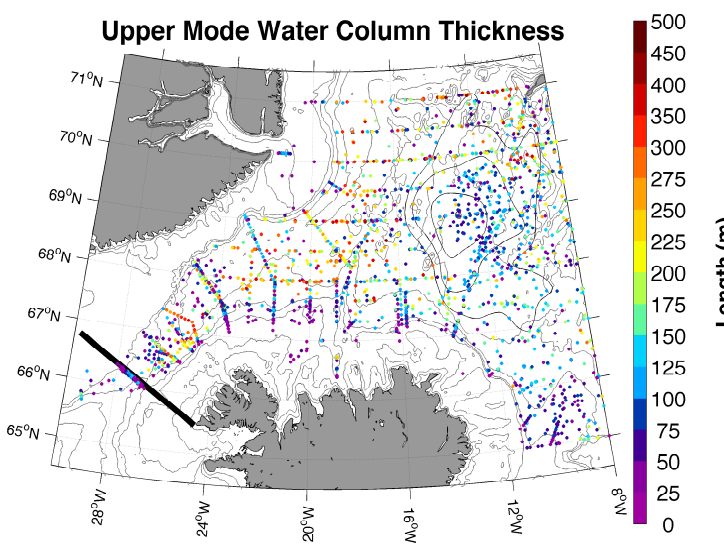

(bi)

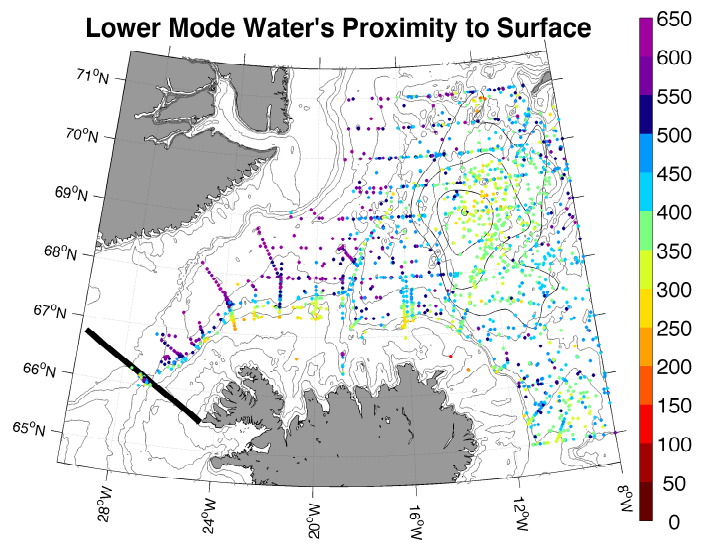

(aii)

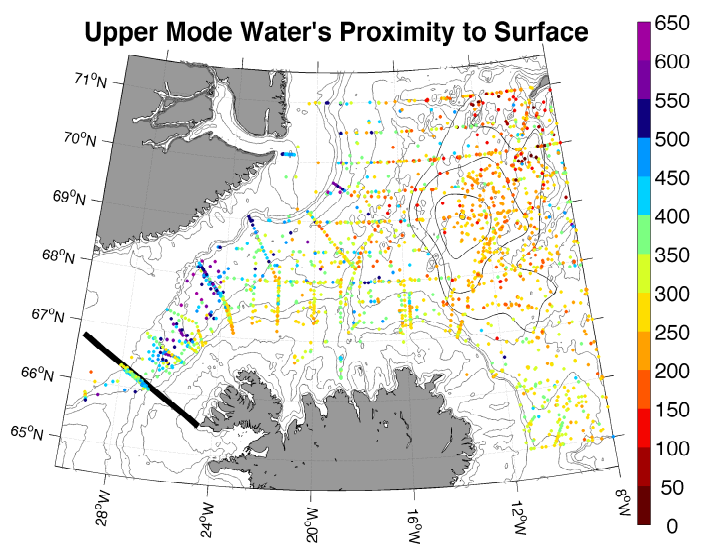

(bii)

Figure B-19: The vertical extent (i) and proximity to the surface (ii) of lower mode (a) and upper mode (b) water in the Nordic Seas. Only water above sill depth $(650 \mathrm{~m})$ is considered. The black contours denote the dynamic height of the Iceland Sea gyre, and the bathymetry is contoured in grey. 


\section{Bibliography}

[1] Aagaard, K., and Malmberg, S.-A.: Low-frequency characteristics of the Denmark Strait overflow, Int. Counc. for the Explor. of the Sea, Copenhagen, 1978.

[2] Bruce, J. G.: Eddies southwest of the Denmark Strait, Deep-Sea Research Part I Oceanographic Research Papers, 42, 13-29, 10.1016/0967-0637(94)00040-y, 1995.

[3] Cooper, L. H. N.: Deep water movements in the North Atlantic as a link between climatic changes around iceland and biological productivity of the english channel and celtic sea, Journal of Marine Research, 14, 347-362, 1955.

[4] CSIRO MATLAB EOS-80 Seawater Library, 3.3 ed., CSIRO Marine and Atmospheric Research, 2010.

[5] Dickson, R. R., and Brown, J.: The production of North Atlantic Deep Water sources, rates, and pathways, Journal of Geophysical Research-Oceans, 99, 12319-12341, 10.1029/94jc00530, 1994.

[6] Dickson, R. R., Meincke, J., and Rhines, P. B.: Arctic-Subarctic Ocean Fluxes: Defining the Role of the Northern Seas in Climate, Springer, Dordrecht, 2008.

[7] Fristedt, T., Hietala, R., and Lundberg, P.: Stability properties of a barotropic surfacewater jet observed in the Denmark Strait, Tellus Series a-Dynamic Meteorology and Oceanography, 51, 979-989, 10.1034/j.1600-0870.1999.00030.x, 1999.

[8] Girton, J. B.: Dynamics of Transport and Variability in the Denmark Strait Overflow, Doctor of Philosophy, School of Oceanography, University of Washington, Seattle, Washington, 2001.

[9] Girton, J. B., and Sanford, T. B.: Descent and modification of the overflow plume in the Denmark Strait, Journal of Physical Oceanography, 33, 1351-1364, 10.1175/15200485(2003)033<1351:damoto $>2.0$. co;2, 2003.

[10] Harden, B. E., Macrander, A., Pickart, R. S., Jonsson, S., Valdimarsson, H., de Steur, L., and Våge, K.: Upstream Sources of the Denmark Strait Overflow: Observations from a High-Resolution Mooring Array, 2015.

[11] Jiang, L., and Garwood, R. W.: Three-dimensional simulations of overflows on continental slopes, Journal of Physical Oceanography, 26, 1214-1233, 10.1175/15200485(1996)026<1214:tdsooo >2.0.co;2, 1996.

[12] Jochumsen, K., Quadfasel, D., Valdimarsson, H., and Jonsson, S.: Variability of the Denmark Strait overflow: Moored time series from 1996-2011, Journal of Geophysical Research-Oceans, 117, 10.1029/2012jc008244, 2012. 
[13] Jonsson, S.: The circulation in the northern part of the Denmark Strait and its variability, Int. Counc. for the Explor. of the Sea, Stockholm, 1999.

[14] Jonsson, S., and Valdimarsson, H.: A new path for the Denmark Strait overflow water from the Iceland Sea to Denmark Strait, Geophysical Research Letters, 31, 10.1029/2003gl019214, 2004.

[15] Jungclaus, J. H., and Backhaus, J. O.: Application of a transient reduced gravity plume model to the denmark strait overflow, Journal of Geophysical Research-Oceans, 99, 12375-12396, 10.1029/94jc00528, 1994.

[16] Käse, R. H., and Oschlies, A.: Flow through Denmark Strait, Journal of Geophysical Research-Oceans, 105, 28527-28546, 10.1029/2000jc900111, 2000.

[17] Käse, R. H., Girton, J. B., and Sanford, T. B.: Structure and variability of the Denmark Strait Overflow: Model and observations, Journal of Geophysical Research-Oceans, 108, 10.1029/2002jc001548, 2003.

[18] Koszalka, I. M., Haine, T. W. N., and Magaldi, M. G.: Fates and Travel Times of Denmark Strait Overflow Water in the Irminger Basin, Journal of Physical Oceanography, 43, 2611-2628, 10.1175/jpo-d-13-023.1, 2013.

[19] Krauss, W.: A note on overflow eddies, Deep-Sea Research Part I-Oceanographic Research Papers, 43, 1661-1667, 10.1016/s0967-0637(96)00073-8, 1996.

[20] Krauss, W., and Käse, R. H.: Eddy formation in the Denmark Strait overflow, Journal of Geophysical Research-Oceans, 103, 15525-15538, 10.1029/98jc00785, 1998.

[21] Macrander, A., Käse, R. H., Send, U., Valdimarsson, H., and Jonsson, S.: Spatial and temporal structure of the Denmark Strait Overflow revealed by acoustic observations, Ocean Dynamics, 57, 75-89, 10.1007/s10236-007-0101-x, 2007.

[22] Mauritzen, C.: Production of dense overflow waters feeding the North Atlantic across the Greenland-Scotland Ridge .1. Evidence for a revised circulation scheme, Deep-Sea Research Part I-Oceanographic Research Papers, 43, 769-806, 10.1016/09670637(96)00037-4, 1996.

[23] Nordic-World Ocean Circulation Experiment Data Set (Nordic WOCE), 1993-1997, Marine Research Institute, Reykjavik, Iceland, 2009.

[24] Pratt, L. J., and Whitehead, J. A.: Nonlinear topographic effects in the ocean and atmosphere, Atmospheric and oceanographic sciences library, 36, Springer, New York, xiii, 589 p. pp., 2008.

[25] Price, J. F., and Baringer, M. O.: Outflows and deep-water production by marginal seas, Progress in Oceanography, 33, 161-200, 10.1016/0079-6611(94)90027-2, 1994.

[26] SBE Data Processing Manual, Sea-Bird Electronics, Inc., Bellevue, Washington, 2014.

[27] Ross, C. K.: Overflow variability in the Denmark Strait., Int. Counc. for the Explor. of the Sea, Copenhagen, 1978. 
[28] Ross, C. K.: Overflow '73, Denmark Strait, Volume 3 : Temperature, salinity, and sigma-t sections, Canadian technical report of hydrography and ocean sciences, Bedford Institute of Oceanography, Dartmouth, Nova Scotia, 1982.

[29] Rudels, B., Eriksson, P., Gronvall, H., Hietala, R., and Launiainen, J.: Hydrographic observations in Denmark Strait in Fall 1997, and their implications for the entrainment into the overflow plume, Geophysical Research Letters, 26, 1325-1328, 10.1029/1999gl900212, 1999.

[30] Rudels, B., Fahrbach, E., Meincke, J., Budeus, G., and Eriksson, P.: The East Greenland Current and its contribution to the Denmark Strait overflow, ICES Journal of Marine Science, 59, 1133-1154, 10.1006/jmsc.2002.1284, 2002.

[31] Shi, X. B., Roed, L. P., and Hackett, B.: Variability of the Denmark Strait overflow: A numerical study, Journal of Geophysical Research-Oceans, 106, 22277-22294, 10.1029/2000jc000642, 2001.

[32] Smith, P. C.: Baroclinic instability in Denmark Strait overflow, Journal of Physical Oceanography, 6, 355-371, 10.1175/1520-0485(1976)006<0355:biitds > 2.0.co;2, 1976.

[33] Smith, W. H. F., and Wessel, P.: Gridding with continuous curvature splines in tension, Geophysics, 55, 293-305, 10.1190/1.1442837, 1990.

[34] Spall, M. A., and Price, J. F.: Mesoscale variability in Denmark Strait: The PV outflow hypothesis, Journal of Physical Oceanography, 28, 1598-1623, 10.1175/15200485(1998)028<1598:mvidst $>2.0$. co;2, 1998.

[35] Tanhua, T., Bulsiewicz, K., and Rhein, M.: Spreading of overflow water from the Greenland to the Labrador Sea, Geophysical Research Letters, 32, 10.1029/2005gl022700, 2005 .

[36] Våge, K., Pickart, R. S., Spall, M. A., Valdimarsson, H., Jonsson, S., Torres, D. J., Osterhus, S., and Eldevik, T.: Significant role of the North Icelandic Jet in the formation of Denmark Strait overflow water, Nature Geoscience, 4, 723-727, 10.1038/ngeo1234, 2011.

[37] Våge, K., Pickart, R. S., Spall, M. A., Moore, G. W. K., Valdimarsson, H., Torres, D. J., Erofeeva, S. Y., and Nilsen, J. E. O.: Revised circulation scheme north of the Denmark Strait, Deep-Sea Research Part I - Oceanographic Research Papers, 79, 20-39, 10.1016/j.dsr.2013.05.007, 2013.

[38] Våge, K., Moore, G. W. K., Jonsson, S., and Valdimarsson, H.: Water mass transformation in the Iceland Sea, Deep-Sea Research Part I-Oceanographic Research Papers, 101, 98-109, 10.1016/j.dsr.2015.04.001, 2015.

[39] Variability of exchanges in the northern seas (VEINS), University of Hamburg, 2000.

[40] von Appen, W. J., Pickart, R. S., Brink, K. H., and Haine, T. W. N.: Water column structure and statistics of Denmark Strait Overflow Water cyclones, Deep-Sea Research Part I-Oceanographic Research Papers, 84, 110-126, 10.1016/j.dsr.2013.10.007, 2014. 
[41] Worthington, L. V.: An attempt to measure the volume transport of Norwegian Sea overflow water through the Denmark Strait, Deep Sea Res. Oceanogr. Abstr, 421-432, 1969. 